\title{
Dynamic Characters of Stiffened Composite Conoidal Shell Roofs with Cutouts: Design Aids and Selection Guidelines
}

\author{
Sarmila Sahoo \\ Department of Civil Engineering, Heritage Institute of Technology, Kolkata 700107, India \\ Correspondence should be addressed to Sarmila Sahoo; sarmila_ju@yahoo.com
}

Received 11 December 2012; Revised 3 May 2013; Accepted 14 May 2013

Academic Editor: Jun Li

Copyright ( 2013 Sarmila Sahoo. This is an open access article distributed under the Creative Commons Attribution License, which permits unrestricted use, distribution, and reproduction in any medium, provided the original work is properly cited.

\begin{abstract}
Dynamic characteristics of stiffened composite conoidal shells with cutout are analyzed in terms of the natural frequency and mode shapes. A finite element code is developed for the purpose by combining an eight-noded curved shell element with a three-noded curved beam element. The code is validated by solving benchmark problems available in the literature and comparing the results. The size of the cutouts and their positions with respect to the shell centre are varied for different edge constraints of cross-ply and angle-ply laminated composite conoids. The effects of these parametric variations on the fundamental frequencies and mode shapes are considered in details. The results furnished here may be readily used by practicing engineers dealing with stiffened composite conoids with cutouts central or eccentric.
\end{abstract}

\section{Introduction}

Laminated composite structures are gaining wide importance in various fields of aerospace and civil engineering. Shell roof structures can be conveniently built with composite materials that have many attributes, besides high specific strength and stiffness. Among the different shell panels which are commonly used as roofing units in civil engineering practice, the conoidal shell has a special position due to a number of advantages it offers. Conoidal shells are often used to cover large column-free areas. Being ruled surfaces, they provide ease of casting and also allow north light in. Hence, this shell is preferred in many places, particularly in medical, chemical, and food processing industries where entry of north light is desirable. Application of conoids in these industries often necessitates cutouts for the passage of light, service lines, and also sometimes for alteration of resonant frequency. In practice, the margin of the cutouts must be stiffened to take account of stress concentration effects. An in-depth study including bending, buckling, vibration, and impact is required to exploit the possibilities of these curved forms. The present investigation is, however, restricted only to the free vibration behaviour. A generalized formulation for the doubly curved laminated composite shell has been presented using the eight-noded curved quadratic isoparametric finite element including three radii of curvature. Some of the important contributions on the investigation of conoidal shells are briefly reviewed here.

The research on conoidal shell started about four decades ago. In 1964, Hadid [1] analysed static characteristics of conoidal shells using the variational method. The research was carried forward and improved by researchers like Brebbia and Hadid [2], Choi [3], Ghosh and Bandyopadhyay [4, 5], Dey et al. [6], and Das and Bandyopadhyay [7]. Dey et al. [6] provided a significant contribution on static analysis of conoidal shell. Chakravorty et al. [8] applied the finite element technique to explore the free vibration characteristics of shallow isotropic conoids and also observed the effects of excluding some of the inertia terms from the mass matrix on the first four natural frequencies. Chakravorty et al. [9-11] published a series of papers where they reported on free and forced vibration characteristics of graphite-epoxy composite conoidal shells with regular boundary conditions. Later, Nayak and Bandyopadhyay [12-15] reported free vibration of stiffened isotropic and composite conoidal shells. Das and Chakravorty $[16,17]$ considered bending and free vibration characteristics of unpunctured and unstiffened composite conoids. Hota and Chakravorty [18] studied isotropic punctured conoidal shells with complicated boundary conditions along the four edges, but no such study about composite 
conoidal shells is available in the literature. Also, they did not furnish any information on vibration mode shapes. It is also seen from the recent reviews $[19,20]$ that dynamic characteristics of stiffened conoidal shells with cutout are still missing in the literature. The present study thus focuses on the free vibrations of graphite-epoxy laminated composite stiffened conoids with cutout both in terms of the natural frequencies and mode shapes. The results so obtained may be readily used by practicing engineers dealing with stiffened composite conoids with cutouts. The novelty of the present study lies in the consideration of vibration mode shapes of stiffened composite conoids in presence of cutouts.

\section{Mathematical Formulation}

A laminated composite conoidal shell of uniform thickness $h$ (Figure 1), and radius of curvature $R_{y}$, and radius of cross curvature $R_{x y}$ is considered. Keeping the total thickness the same, the thickness may consist of any number of thin laminae each of which may be arbitrarily oriented at an angle $\theta$ with reference to the $x$-axis of the coordinate system. The constitutive equations for the shell are given by (a list of notations is separately given)

$$
\{F\}=[E]\{\varepsilon\},
$$

where

$$
\begin{aligned}
& \{F\}=\left\{N_{x}, N_{y}, N_{x y}, M_{x}, M_{y}, M_{x y}, Q_{x}, Q_{y}\right\}^{T}, \\
& {[E]=\left[\begin{array}{ccc}
{[A]} & {[B]} & {[0]} \\
{[B]} & {[D]} & {[0]} \\
{[0]} & {[0]} & {[S]}
\end{array}\right],} \\
& \{\varepsilon\}=\left\{\varepsilon_{x}^{0}, \varepsilon_{y}^{0}, \gamma_{x y}^{0}, k_{x}, k_{x y}, \gamma_{x z}^{0}, \gamma_{y z}^{0}\right\}^{T} .
\end{aligned}
$$

The force and moment resultants are expressed as

$$
\begin{aligned}
& \left\{N_{x}, N_{y}, N_{x y}, M_{x}, M_{y}, M_{x y}, Q_{x}, Q_{y}\right\}^{T} \\
& \quad=\int_{-h / 2}^{h / 2}\left\{\sigma_{x}, \sigma_{y}, \tau_{x y}, \sigma_{z} \cdot z, \sigma_{y} \cdot z, \tau_{x y} \cdot z, \tau_{x z}, \tau_{y z}\right\}^{T} d z .
\end{aligned}
$$

The submatrices $[A],[B],[D]$, and $[S]$ of the elasticity matrix $[E]$ are functions of Young's moduli, shear moduli, and Poisson's ratio of the laminates. They also depend on the angle which the individual lamina of a laminate makes with the global $x$-axis. The detailed expressions of the elements of the elasticity matrix are available in several references including Vasiliev et al. [21] and Qatu [22].

The strain-displacement relations on the basis of improved first-order approximation theory for thin shell (Dey et al. [6]) are established as

$$
\begin{aligned}
& \left\{\varepsilon_{x}, \varepsilon_{y}, \gamma_{x y}, \gamma_{x z}, \gamma_{y z}\right\}^{T} \\
& \quad=\left\{\varepsilon_{x}^{0}, \varepsilon_{y}^{0}, \gamma_{x y}^{0}, \gamma_{x z}^{0}, \gamma_{y z}^{0}\right\}^{T}+z\left\{k_{x}, k_{y}, k_{x y}, k_{x z}, k_{y z}\right\}^{T},
\end{aligned}
$$

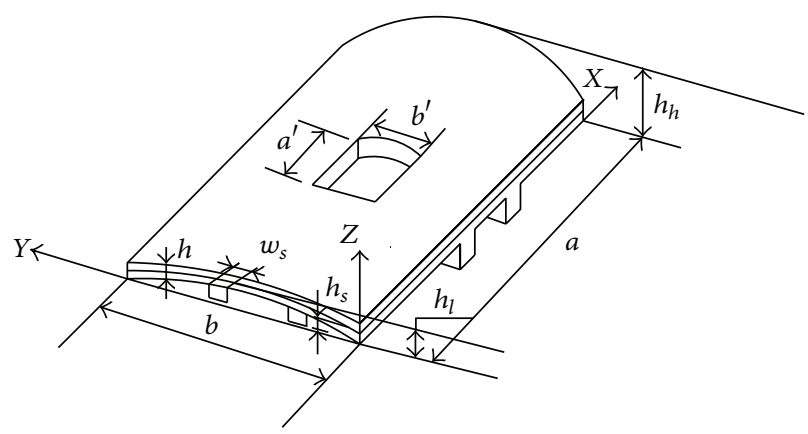

FIGURE 1: Conoidal shell with a concentric cutout stiffened along the margins.

where the first vector is the midsurface strain for a conoidal shell and the second vector is the curvature.

\section{Finite Element Formulation}

3.1. Finite Element Formulation for Shell. An eight-noded curved quadratic isoparametric finite element is used for conoidal shell analysis. The five degrees of freedom taken into consideration at each node are $u, v, w, \alpha, \beta$. The following expressions establish the relations between the displacement at any point with respect to the coordinates $\xi$ and $\eta$ and the nodal degrees of freedom

$$
\begin{gathered}
u=\sum_{i=1}^{8} N_{i} u_{i}, \quad v=\sum_{i=1}^{8} N_{i} v_{i}, \quad w=\sum_{i=1}^{8} N_{i} w_{i}, \\
\alpha=\sum_{i=1}^{8} N_{i} \alpha_{i}, \quad \beta=\sum_{i=1}^{8} N_{i} \beta_{i},
\end{gathered}
$$

where the shape functions derived from a cubic interpolation polynomial [6] are

$$
\begin{gathered}
N_{i}=\frac{\left(1+\xi \xi_{i}\right)\left(1+\eta \eta_{i}\right)\left(\xi \xi_{i}+\eta \eta_{i}-1\right)}{4}, \quad \text { for } i=1,2,3,4, \\
N_{i}=\frac{\left(1+\xi \xi_{i}\right)\left(1-\eta^{2}\right)}{2}, \quad \text { for } i=5,7, \\
N_{i}=\frac{\left(1+\eta \eta_{i}\right)\left(1-\xi^{2}\right)}{2}, \quad \text { for } i=6,8 .
\end{gathered}
$$

The generalized displacement vector of an element is expressed in terms of the shape functions and nodal degrees of freedom as

$$
[u]=[N]\left\{d_{e}\right\}
$$

that is,

$$
\{u\}=\left\{\begin{array}{c}
u \\
v \\
w \\
\alpha \\
\beta
\end{array}\right\}=\sum_{i=1}^{8}\left[\begin{array}{ccccc}
N_{i} & & & & \\
& N_{i} & & & \\
& & N_{i} & & \\
& & & N_{i} & \\
& & & & N_{i}
\end{array}\right]\left\{\begin{array}{c}
u_{i} \\
v_{i} \\
w_{i} \\
\alpha_{i} \\
\beta_{i}
\end{array}\right\} .
$$


3.1.1. Element Stiffness Matrix. The strain-displacement relation is given by

$$
\{\varepsilon\}=[B]\left\{d_{e}\right\},
$$

where

$$
[B]=\sum_{i=1}^{8}\left[\begin{array}{ccccc}
N_{i, x} & 0 & 0 & 0 & 0 \\
0 & N_{i, y} & -\frac{N_{i}}{R_{y}} & 0 & 0 \\
& & & \\
N_{i, y} & N_{i, x} & -\frac{2 N_{i}}{R_{x y}} & 0 & 0 \\
0 & 0 & 0 & N_{i, x} & 0 \\
0 & 0 & 0 & 0 & N_{i, y} \\
0 & 0 & 0 & N_{i, y} & N_{i, x} \\
0 & 0 & N_{i, x} & N_{i} & 0 \\
0 & 0 & N_{i, y} & 0 & N_{i}
\end{array}\right] .
$$

The element stiffness matrix is

$$
\left[K_{e}\right]=\iint[B]^{T}[E][B] d x d y .
$$

3.1.2. Element Mass Matrix. The element mass matrix is obtained from the integral

$$
\left[M_{e}\right]=\iint[N]^{T}[P][N] d x d y,
$$

where

$$
\begin{gathered}
{[N]=\sum_{i=1}^{8}\left[\begin{array}{ccccc}
N_{i} & 0 & 0 & 0 & 0 \\
0 & N_{i} & 0 & 0 & 0 \\
0 & 0 & N_{i} & 0 & 0 \\
0 & 0 & 0 & N_{i} & 0 \\
0 & 0 & 0 & 0 & N_{i}
\end{array}\right],} \\
{[P]=\sum_{i=1}^{8}\left[\begin{array}{lllll}
P & 0 & 0 & 0 & 0 \\
0 & P & 0 & 0 & 0 \\
0 & 0 & P & 0 & 0 \\
0 & 0 & 0 & I & 0 \\
0 & 0 & 0 & 0 & I
\end{array}\right],}
\end{gathered}
$$

in which

$$
P=\sum_{k=1}^{n p} \int_{z_{k-1}}^{z_{k}} \rho d z, \quad I=\sum_{k=1}^{n p} \int_{z_{k-1}}^{z_{k}} z \rho d z .
$$

3.2. Finite Element Formulation for Stiffener of the Shell. Three-noded curved isoparametric beam element (Figure 2) are used to model the stiffeners, which are taken to run only along the boundaries of the shell elements. In the stiffener element, each node has four degrees of freedom, that is, $u_{s x}$, $w_{s x}, \alpha_{s x}$, and $\beta_{s x}$ for $X$-stiffener and $v_{s y}, w_{s y}, \alpha_{s y}$, and $\beta_{s y}$ for $Y$-stiffener. The generalized force-displacement relation of stiffeners can be expressed as

$$
\begin{gathered}
X \text {-stiffener: }\left\{F_{s x}\right\}=\left[D_{s x}\right]\left\{\varepsilon_{s x}\right\}=\left[D_{s x}\right]\left[B_{s x}\right]\left\{\delta_{s x i}\right\}, \\
Y \text {-stiffener: }\left\{F_{s y}\right\}=\left[D_{s y}\right]\left\{\varepsilon_{s y}\right\}=\left[D_{s y}\right]\left[B_{s y}\right]\left\{\delta_{s y i}\right\},
\end{gathered}
$$

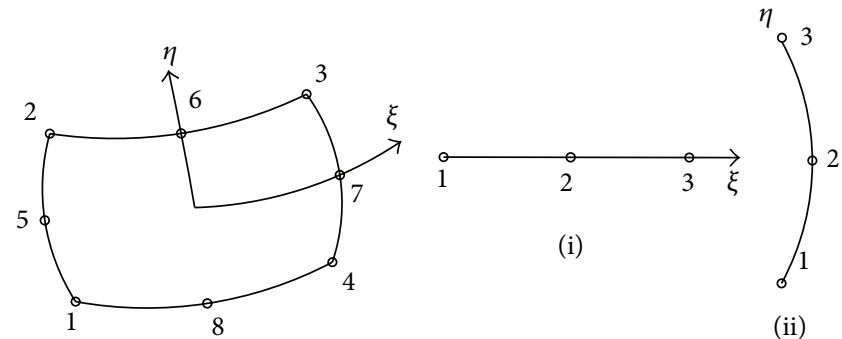

(a)

(b)

FIGURE 2: (a) Eight-noded shell element with isoparametric coordinates. (b) Three-noded stiffener element: (i) $X$-stiffener (ii) $Y$ stiffener.

where

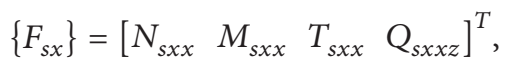

$$
\begin{aligned}
& \left\{\varepsilon_{s x}\right\}=\left[\begin{array}{llll}
u_{s x \cdot x} & \alpha_{s x \cdot x} & \beta_{s x \cdot x} & \left(\alpha_{s x}+w_{s x \cdot x}\right)
\end{array}\right]^{T}, \\
& \left\{F_{s y}\right\}=\left[\begin{array}{llll}
N_{s y y} & M_{s y y} & T_{s y y} & Q_{s y y z}
\end{array}\right]^{T}, \\
& \left\{\varepsilon_{s y}\right\}=\left[\begin{array}{llll}
v_{s y \cdot y} & \beta_{s y \cdot y} & \alpha_{s y \cdot y} & \left(\beta_{s y}+w_{s y \cdot y}\right)
\end{array}\right]^{T} .
\end{aligned}
$$

The generalized displacements of the $Y$-stiffener and the shell are related by the transformation matrix $\left\{\delta_{s y i}\right\}=[T]\{\delta\}$, where

$$
[T]=\left[\begin{array}{ccccc}
1+\frac{e}{R_{y}} & \text { symmetric } & & \\
0 & 1 & & \\
0 & 0 & 1 & \\
0 & 0 & 0 & 1
\end{array}\right] .
$$

This transformation is required due to curvature of $Y$-stiffener, and $\{\delta\}$ is the appropriate portion of the displacement vector of the shell excluding the displacement component along the $x$-axis.

Elasticity matrices are as follows:

$$
\begin{aligned}
& {\left[D_{s x}\right]=\left[\begin{array}{cccc}
A_{11} b_{s x} & B_{11}^{\prime} b_{s x} & B_{12}^{\prime} b_{s x} & 0 \\
B_{11}^{\prime} b_{s x} & D_{11}^{\prime} b_{s x} & D_{12}^{\prime} b_{s x} & 0 \\
B_{12}^{\prime} b_{s x} & D_{12}^{\prime} b_{s x} & \frac{1}{6}\left(Q_{44}+Q_{66}\right) d_{s x} b_{s x}^{3} & 0 \\
0 & 0 & 0 & b_{s x} S_{11}
\end{array}\right],} \\
& {\left[D_{s y}\right]=\left[\begin{array}{cccc}
A_{22} b_{s y} & B_{22}^{\prime} b_{s y} & B_{12}^{\prime} b_{s y} & 0 \\
B_{22}^{\prime} b_{s y} & \frac{1}{6}\left(Q_{44}+Q_{66}\right) b_{s y} & D_{12}^{\prime} b_{s y} & 0 \\
B_{12}^{\prime} b_{s y} & D_{12}^{\prime} b_{s y} & D_{11}^{\prime} d_{s y} b_{s y}^{3} & 0 \\
0 & 0 & 0 & b_{s y} S_{22}
\end{array}\right],}
\end{aligned}
$$

where

$$
\begin{gathered}
D_{i j}^{\prime}=D_{i j}+2 e B_{i j}+e^{2} A_{i j}, \\
B_{i j}^{\prime}=B_{i j}+e A_{i j},
\end{gathered}
$$


and $A_{i j}, B_{i j}, D_{i j}$, and $S_{i j}$ are explained in an earlier paper by Sahoo and Chakravorty [23].

Here, the shear correction factor is taken as $5 / 6$. The sectional parameters are calculated with respect to the midsurface of the shell by which the effect of eccentricities of stiffeners is automatically included. The element stiffness matrices are of the following forms:

$$
\begin{aligned}
& \text { for } X \text {-stiffener: }\left[K_{x e}\right]=\int\left[B_{s x}\right]^{T}\left[D_{s x}\right]\left[B_{s x}\right] d x \text {, } \\
& \text { for } Y \text {-stiffener: }\left[K_{y e}\right]=\int\left[B_{s y}\right]^{T}\left[D_{s y}\right]\left[B_{s y}\right] d y \text {. }
\end{aligned}
$$

The integrals are converted to isoparametric coordinates and are carried out by 2-point Gauss quadrature. Finally, the element stiffness matrix of the stiffened shell is obtained by appropriate matching of the nodes of the stiffener and shell elements through the connectivity matrix and is given as

$$
\left[K_{e}\right]=\left[K_{\text {she }}\right]+\left[K_{x e}\right]+\left[K_{y e}\right] .
$$

The element stiffness matrices are assembled to get the global matrices.

\subsubsection{Element Mass Matrix. The element mass matrix for shell} is obtained from the integral

$$
\left[M_{e}\right]=\iint[N]^{T}[P][N] d x d y
$$

where

$$
\begin{gathered}
{[N]=\sum_{i=1}^{8}\left[\begin{array}{ccccc}
N_{i} & 0 & 0 & 0 & 0 \\
0 & N_{i} & 0 & 0 & 0 \\
0 & 0 & N_{i} & 0 & 0 \\
0 & 0 & 0 & N_{i} & 0 \\
0 & 0 & 0 & 0 & N_{i}
\end{array}\right],} \\
{[P]=\sum_{i=1}^{8}\left[\begin{array}{ccccc}
P & 0 & 0 & 0 & 0 \\
0 & P & 0 & 0 & 0 \\
0 & 0 & P & 0 & 0 \\
0 & 0 & 0 & I & 0 \\
0 & 0 & 0 & 0 & I
\end{array}\right]}
\end{gathered}
$$

in which

$$
P=\sum_{k=1}^{n p} \int_{z_{k-1}}^{z_{k}} \rho d z, \quad I=\sum_{k=1}^{n p} \int_{z_{k-1}}^{z_{k}} z \rho d z .
$$

Element mass matrix for stiffener element

$$
\begin{aligned}
& {\left[M_{s x}\right]=\iint[N]^{T}[P][N] d x \quad \text { for } X \text {-stiffener, }} \\
& {\left[M_{s y}\right]=\iint[N]^{T}[P][N] d y \quad \text { for } Y \text {-stiffener. }}
\end{aligned}
$$

Here, $[N]$ is a $3 \times 3$ diagonal matrix.

\section{Consider}

$[P]=\sum_{i=1}^{3}\left[\begin{array}{cccc}\rho \cdot b_{s x} d_{s x} & 0 & 0 & 0 \\ 0 & \rho \cdot b_{s x} d_{s x} & 0 & 0 \\ 0 & 0 & \frac{\rho \cdot b_{s x} d_{s x}^{2}}{12} & 0 \\ 0 & 0 & 0 & \frac{\rho\left(b_{s x} \cdot d_{s x}^{3}+b_{s x}^{3} \cdot d_{s x}\right)}{12}\end{array}\right]$

for $X$-stiffener,

$$
[P]=\sum_{i=1}^{3}\left[\begin{array}{cccc}
\rho \cdot b_{s y} d_{s y} & 0 & 0 & 0 \\
0 & \rho \cdot b_{s y} d_{s y} & 0 & 0 \\
0 & 0 & \frac{\rho \cdot b_{s y} d_{s y}^{2}}{12} & 0 \\
0 & 0 & 0 & \frac{\rho\left(b_{s y} \cdot d_{s y}^{3}+b_{s y}^{3} \cdot d_{s y}\right)}{12}
\end{array}\right]
$$

The mass matrix of the stiffened shell element is the sum of the matrices of the shell and the stiffeners matched at the appropriate nodes

$$
\left[M_{e}\right]=\left[M_{\text {she }}\right]+\left[M_{x e}\right]+\left[M_{y e}\right] .
$$

The element mass matrices are assembled to get the global matrices.

3.3. Modeling the Cutout. The code developed can take the position and size of cutout as input. The program is capable of generating nonuniform finite element mesh all over the shell surface. So, the element size is gradually decreased near the cutout margins. One such typical mesh arrangement is shown in Figure 3. Such finite element mesh is redefined in steps, and a particular grid is chosen to obtain the fundamental frequency when the result does not improve by more than one percent on further refining. Convergence of results is ensured in all the problems taken up here.

3.4. Solution Procedure for Free Vibration Analysis. The free vibration analysis involves determination of natural frequencies from the condition

$$
\left|[K]-\omega^{2}[M]\right|=0 .
$$

This is a generalized eigen value problem and is solved by the subspace iteration algorithm.

\section{Numerical Examples}

The validity of the present approach is checked through solution of benchmark problems. The first problem, free vibration of stiffened clamped conoid, was solved earlier by Nayak and Bandyopadhyay [13]. The second is the free vibration of composite conoid with cutouts solved by Chakravorty et al. [11]. The results obtained by the present method, along with the published results, are presented in Tables 1 and 2, respectively.

Additional problems for conoids with cutouts are solved, varying the size and position of cutout along both of the plan 
TABLE 1: Fundamental frequencies ( $\mathrm{rad} / \mathrm{sec}$ ) of clamped conoidal shell with central stiffeners.

\begin{tabular}{|c|c|c|c|c|c|c|c|c|c|c|c|c|}
\hline \multirow{3}{*}{$\begin{array}{l}\text { Stiffener } \\
\text { position }\end{array}$} & \multicolumn{4}{|c|}{ Stiffener along $x$-direction } & \multicolumn{4}{|c|}{ Stiffener along $y$-direction } & \multicolumn{4}{|c|}{ Stiffener along both $x$ - and $y$-directions } \\
\hline & \multirow{2}{*}{$\begin{array}{c}\text { Nayak and } \\
\text { Bandyopadhyay } \\
{[13]}\end{array}$} & \multicolumn{3}{|c|}{ Present model } & \multirow{2}{*}{$\begin{array}{c}\text { Nayak and } \\
\text { Bandyopadhyay } \\
{[13]}\end{array}$} & \multicolumn{3}{|c|}{ Present model } & \multirow{2}{*}{$\begin{array}{c}\text { Nayak and } \\
\text { Bandyopadhyay } \\
{[13]}\end{array}$} & \multicolumn{3}{|c|}{ Present model } \\
\hline & & $8 \times 8$ & $10 \times 10$ & $12 \times 12$ & & $8 \times 8$ & $10 \times 10$ & $12 \times 12$ & & $8 \times 8$ & $10 \times 10$ & $12 \times 12$ \\
\hline Concentric & 17.28 & 17.50 & 17.37 & 17.31 & 20.83 & 21.15 & 20.85 & 20.76 & 20.90 & 21.24 & 21.01 & 20.84 \\
\hline $\begin{array}{l}\text { Eccentric at } \\
\text { top }\end{array}$ & 17.83 & 17.92 & 17.78 & 17.73 & 21.57 & 21.76 & 21.53 & 21.45 & 22.39 & 22.86 & 22.51 & 22.32 \\
\hline $\begin{array}{l}\text { Eccentric at } \\
\text { bottom }\end{array}$ & 17.55 & 17.80 & 17.61 & 17.52 & 22.31 & 22.66 & 22.40 & 22.24 & 22.92 & 23.25 & 23.00 & 22.87 \\
\hline
\end{tabular}

$a=50 \mathrm{~m}, b=50 \mathrm{~m}, h=0.2 \mathrm{~m}, h_{h}=10 \mathrm{~m}, h_{l}=2.5 \mathrm{~m}, E=25.4910 \times 10^{9}, v=0.15, \rho=2500 \mathrm{~kg} / \mathrm{m}^{3}, w_{s}=0.3 \mathrm{~m}$, and $h_{s}=1 \mathrm{~m}$.

TABLE 2: Nondimensional fundamental frequencies $(\bar{\omega})$ for laminated composite conoidal shell with cutout.

\begin{tabular}{lcccccc}
\hline \multirow{2}{*}{$a^{\prime} / a$} & \multicolumn{2}{c}{ Corner point supported } & \multicolumn{2}{c}{ Simply supported } & \multicolumn{2}{c}{ Clamped } \\
& Chakravorty et al. [11] & Present model & Chakravorty et al. [11] & Present model & Chakravorty et al. [11] & Present model \\
\hline 0.0 & 23.863 & 23.494 & 75.450 & 74.892 & 124.736 & 123.306 \\
0.1 & 23.554 & 23.872 & 75.098 & 75.278 & 123.811 & 123.987 \\
0.2 & 23.746 & 23.485 & 73.668 & 73.324 & 122.074 & 120.588 \\
0.3 & 23.510 & 23.768 & 69.979 & 69.763 & 120.515 & 119.101 \\
0.4 & 23.205 & 23.101 & 61.824 & 61.524 & 116.924 & 115.924 \\
\hline
\end{tabular}

$a / b=1, a / h=100, a^{\prime} / b^{\prime}=1, a / h_{h}=2.5$, and $h_{l} / h_{h}=0.25$.

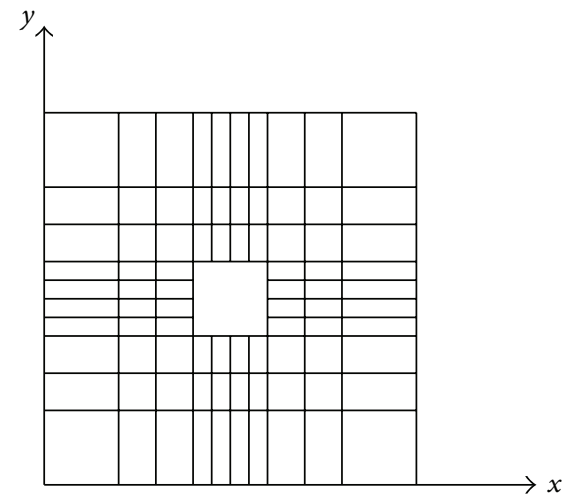

Figure 3: Typical $10 \times 10$ nonuniform mesh arrangements drawn to scale.

directions of the shell for different practical boundary conditions. In order to study the effect of cutout size on the free vibration response, results for unpunctured conoids are also included in the study.

\section{Results and Discussion}

It is found from Table 1 that the fundamental frequencies of stiffened conoids obtained by the present method agree well with those reported by Nayak and Bandyopadhyay [13]. Here, monotonic convergence is noted as the mesh is made progressively finer. Thus, the correctness of the stiffened shell element used here is established. It is evident from Table 2 that the present results agree with those of Chakravorty et al. [11], and the fact that the cutouts are properly modeled in the present formulation is thus established.
5.1. Free Vibration Behaviour of Shells with Concentric Cutouts. Tables 3 and 4 show the results for the non-dimensional fundamental frequency $\bar{\omega}$ of composite cross-ply and angle-ply stiffened conoidal shells for different cutout sizes and various combinations of boundary conditions along the four edges. The shells considered are of square planform $(a=b)$, and the cutouts are also taken to be square in plan $\left(a^{\prime}=b^{\prime}\right)$. The cutout sizes (i.e., $a^{\prime} / a$ ) are varied from 0 to 0.4 , and boundary conditions are varied along the four edges. Cutouts are concentric on shell surface. The stiffeners are placed along the cutout periphery and extended up to the edge of the shell. The boundary conditions are designated by describing the support clamped or simply supported as $\mathrm{C}$ or $\mathrm{S}$ taken in an anticlockwise order from the edge $x=0$. This means that a shell with CSCS boundary is clamped along $x=0$, simply supported along $y=0$, clamped along $x=a$, and simply supported along $y=b$. The material and geometric properties of shells and cutouts are mentioned along with the figures.

5.1.1. Effect of Cutout Size on Fundamental Frequency. From Tables 3 and 4 , it is seen that when a cutout is introduced to a stiffened shell, the fundamental frequencies increase. This increasing trend continues up to $a^{\prime} / a=0.4$ for both cross- and angle ply shells except some angle ply shells with $a^{\prime} / a>0.2$. The initial increase in frequency may be explained by the fact that when a cutout is introduced to an unpunctured surface, the number of stiffeners increases from two to four in the present study. When the cutout size is further increased, the number and dimensions of the stiffeners do not change, but the shell surface undergoes loss of both mass and stiffness. As the cutout grows in size, the loss of mass is more significant than that of stiffness, and hence 


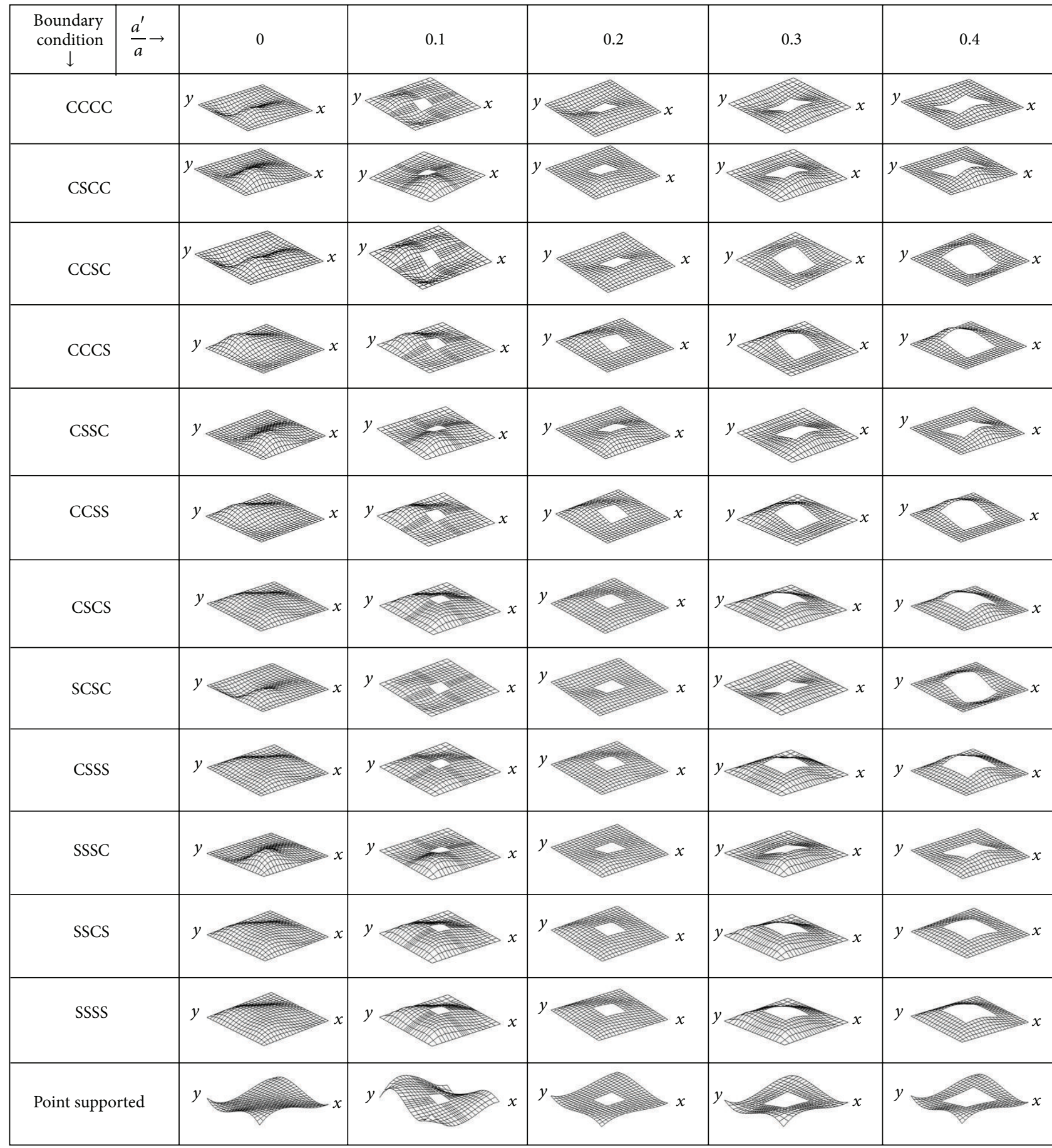

Figure 4: First mode shapes of laminated composite (0/90/0/90) stiffened conoidal shell for different sizes of the central square cutout and boundary conditions.

the frequency increases. But for some angle ply shells with further increase in the size of the cutout, the loss of stiffness gradually becomes more important than that of mass, resulting in decrease in fundamental frequency. This leads to the engineering conclusion that cutouts with stiffened margins may always safely be provided on shell surfaces for functional requirements.
5.1.2. Effect of Boundary Conditions on Fundamental Frequency. The boundary conditions may be divided into six groups, considering number of boundary constraints. The combinations in a particular group have equal number of boundary reactions. These groups are

Group I: CCCC shells,

Group II: CSCC, CCSC, and SCCC shells, 


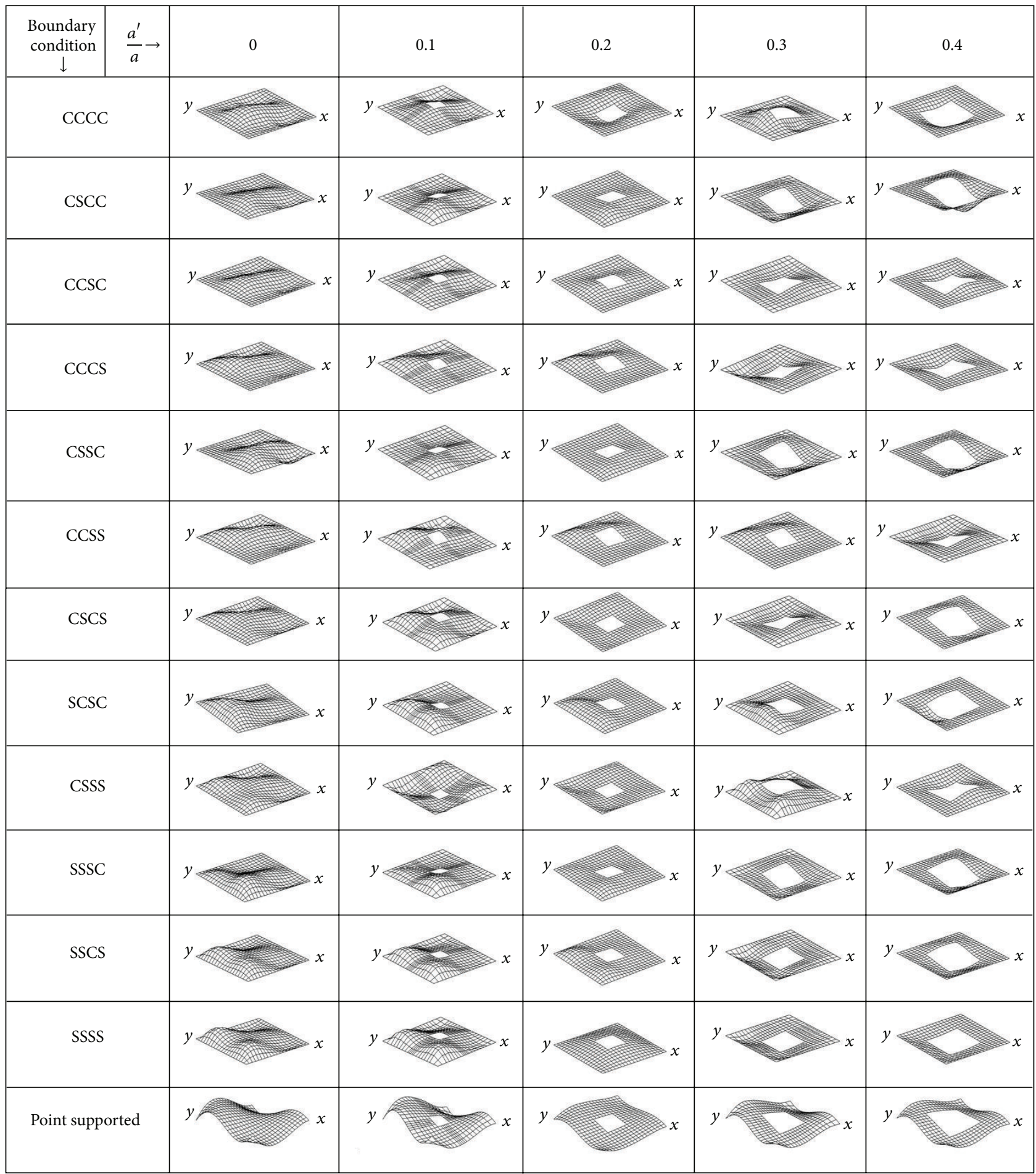

Figure 5: First mode shapes of laminated composite $(+45 /-45 /+45 /-45)$ stiffened conoidal shell for different sizes of the central square cutout and boundary conditions.

Group III: CSSC, SSCC, CSCS, and SCSC shells,

Group IV: CSSS, SSSC, and SSCS shells,

Group V: SSSS shells,

Group VI: Corner point supported shell.
It is seen from Tables 3 and 4 that fundamental frequencies of members belonging to the same groups of boundary combinations may not have close values. So, the different boundary conditions may be regrouped according to performance. According to the values of $\bar{\omega}$, the following groups may be identified. 


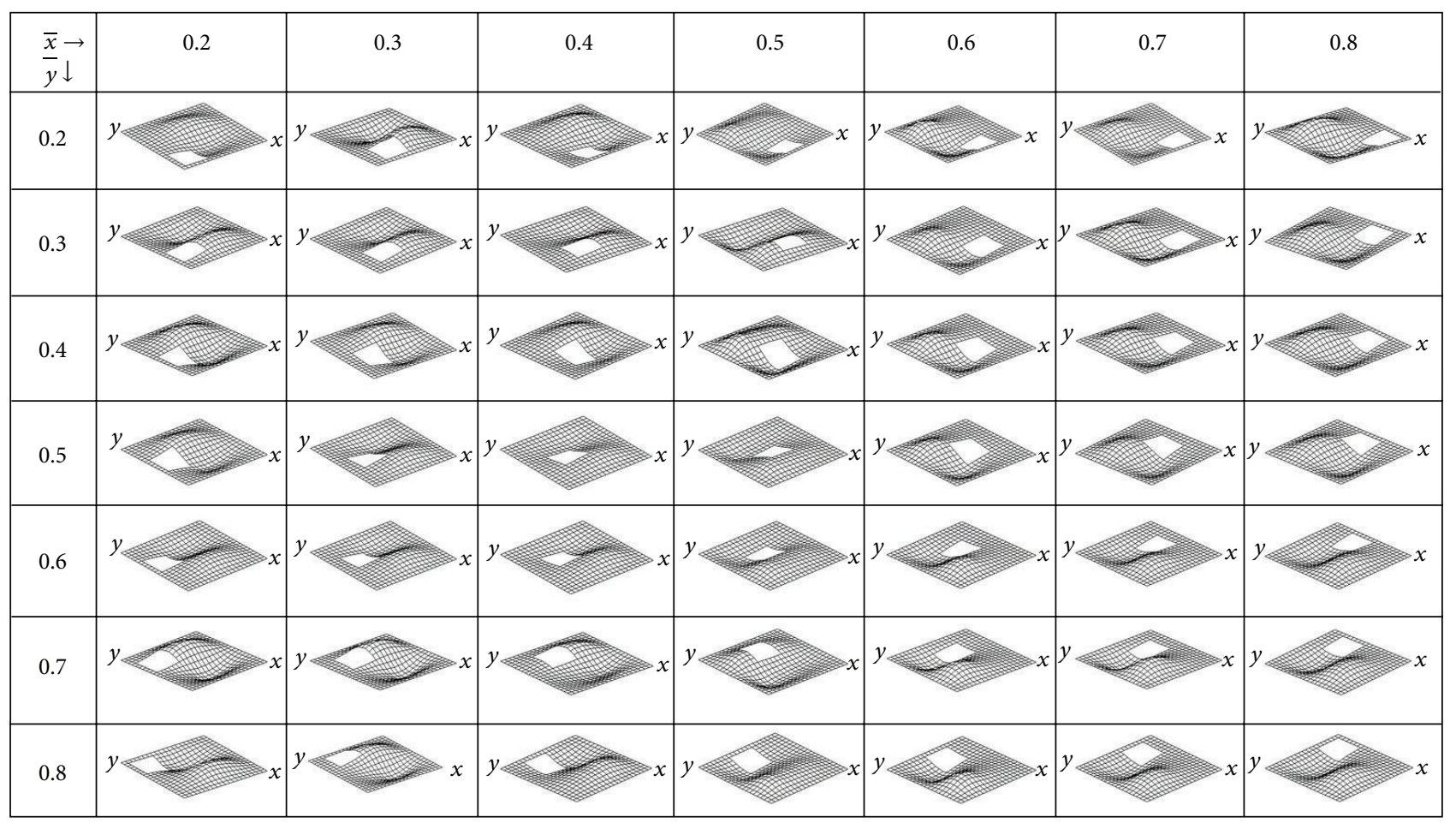

FIGURE 6: First mode shapes of laminated composite (0/90/0/90) stiffened conoidal shell for different positions of the square cutout with CCCC boundary condition.

\begin{tabular}{|c|c|c|c|c|c|c|c|}
\hline$\frac{\bar{x}}{y} \downarrow$ & 0.2 & 0.3 & 0.4 & 0.5 & 0.6 & 0.7 & 0.8 \\
\hline 0.2 & & & & & & & \\
\hline 0.3 & & & & & & & \\
\hline 0.4 & & & & & & & \\
\hline 0.5 & & & & & & & \\
\hline 0.6 & & & & & & & \\
\hline 0.7 & & & & & & & \\
\hline 0.8 & & & & & & & \\
\hline
\end{tabular}

FIGURE 7: First mode shapes of laminated composite (0/90/0/90) stiffened conoidal shell for different positions of the square cutout with CCSC boundary condition. 


\begin{tabular}{|c|c|c|c|c|c|c|c|}
\hline$\frac{\bar{x}}{\bar{y} \downarrow}$ & 0.2 & 0.3 & 0.4 & 0.5 & 0.6 & 0.7 & 0.8 \\
\hline 0.2 & & & & & & & \\
\hline 0.3 & & & & & & & \\
\hline 0.4 & & & & & & & \\
\hline 0.5 & & & & & & & \\
\hline 0.6 & & & & & & & \\
\hline 0.7 & & & & & & & \\
\hline 0.8 & & & & & & & \\
\hline
\end{tabular}

FIGURE 8: First mode shapes of laminated composite $(+45 /-45 /+45 /-45)$ stiffened conoidal shell for different positions of the square cutout with CCCC boundary condition.

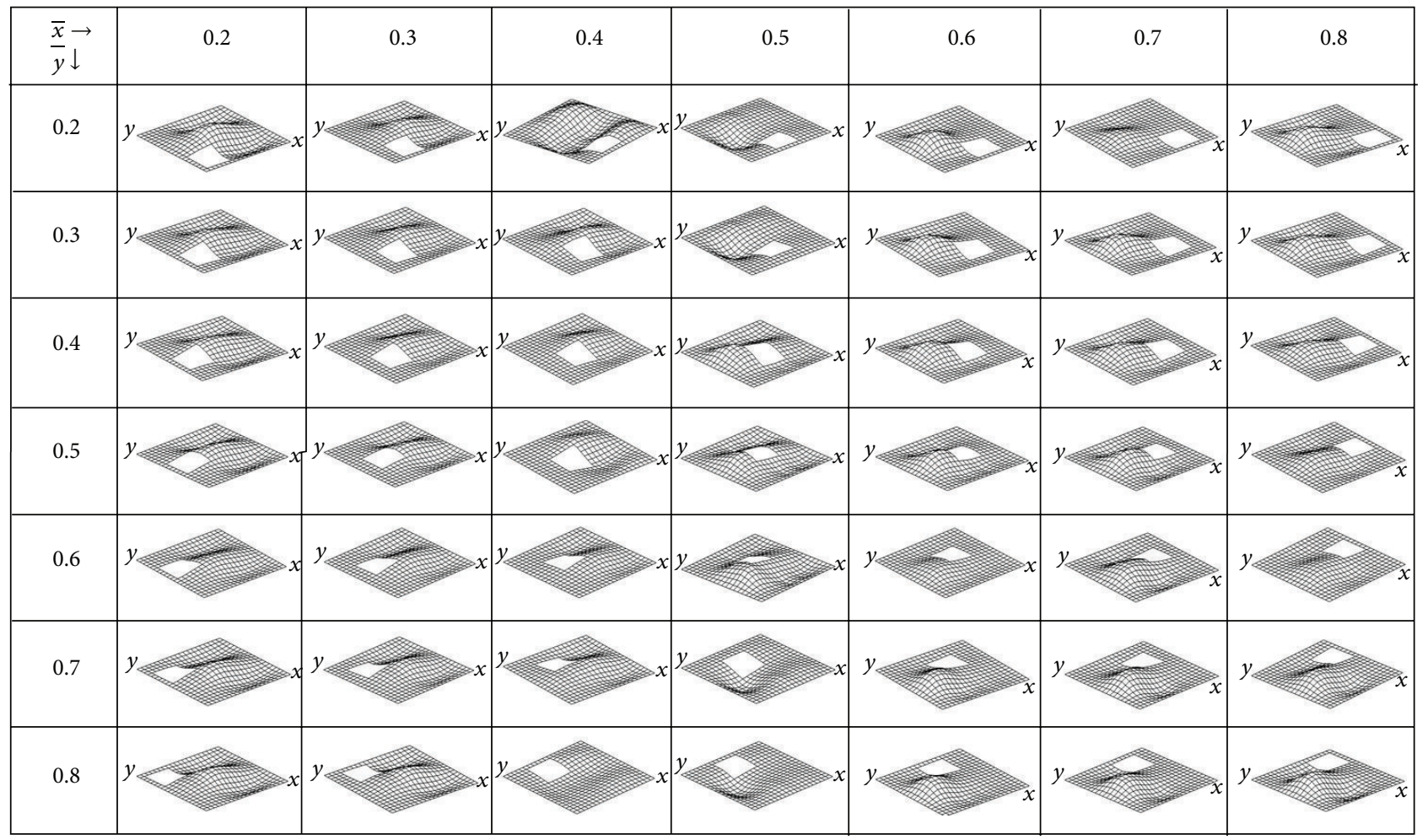

Figure 9: First mode shapes of laminated composite $(+45 /-45 /+45 /-45)$ stiffened conoidal shell for different positions of the square cutout with CCSC boundary condition. 
TABle 3: Non-dimensional fundamental frequencies $(\bar{\omega})$ for laminated composite $(0 / 90 / 0 / 90)$ stiffened conoidal shell for different sizes of the central square cutout and different boundary conditions.

\begin{tabular}{lccccc}
\hline Boundary & \multicolumn{5}{c}{ Cutout size $\left(a^{\prime} / a\right)$} \\
conditions & 0 & 0.1 & 0.2 & 0.3 & 0.4 \\
\hline CCCC & 105.7679 & 118.9136 & 124.386 & 127.4786 & 124.4929 \\
CSCC & 79.3544 & 87.8992 & 91.4718 & 96.4778 & 97.0499 \\
CCSC & 104.0259 & 117.3182 & 120.8486 & 122.5918 & 119.586 \\
CCCS & 79.0009 & 86.457 & 91.1477 & 95.8592 & 97.0069 \\
CSSC & 76.7919 & 84.417 & 87.445 & 91.1546 & 90.359 \\
CCSS & 76.4645 & 83.126 & 87.1684 & 90.6361 & 90.3194 \\
CSCS & 70.8733 & 76.0322 & 80.215 & 86.5974 & 91.9972 \\
SCSC & 96.4607 & 106.1886 & 112.2644 & 116.5409 & 114.8718 \\
CSSS & 65.7562 & 69.5302 & 72.8659 & 77.5964 & 81.1403 \\
SSSC & 65.7398 & 70.72 & 75.0802 & 79.9808 & 82.2204 \\
SSCS & 62.3308 & 65.2487 & 69.3811 & 74.7187 & 80.4246 \\
SSSS & 54.7734 & 56.6793 & 59.276 & 62.3683 & 65.2097 \\
Point & 21.1813 & 21.686 & 22.6166 & 24.2309 & 25.5361 \\
supported & & & & & \\
\hline
\end{tabular}

$a / b=1, a / h=100, a^{\prime} / b^{\prime}=1, a / h_{h}=5, h_{l} / h_{h}=0.25, E_{11} / E_{22}=25, G_{23}=$ $0.2 E_{22}, G_{13}=G_{12}=0.5 E_{22}$, and $v_{12}=v_{21}=0.25$.

TABLE 4: Non-dimensional fundamental frequencies $(\bar{\omega})$ for laminated composite $(+45 /-45 /+45 /-45)$ stiffened conoidal shell for different sizes of the central square cutout and different boundary conditions.

\begin{tabular}{lccccc}
\hline $\begin{array}{l}\text { Boundary } \\
\text { conditions }\end{array}$ & 0 & 0.1 & 0.2 & 0.3 & 0.4 \\
\hline CCCC & 137.5363 & 149.748 & 156.932 & 154.6134 & 147.0345 \\
CSCC & 127.6366 & 139.9845 & 142.6213 & 142.2069 & 133.7437 \\
CCSC & 133.1847 & 157.494 & 165.9908 & 157.6214 & 149.8912 \\
CCCS & 123.9139 & 136.05 & 139.2721 & 140.9553 & 134.9193 \\
CSSC & 119.3132 & 129.2799 & 129.5345 & 119.8123 & 107.4374 \\
CCSS & 114.1784 & 124.2418 & 126.9562 & 119.4147 & 107.3405 \\
CSCS & 119.1939 & 129.2601 & 133.1178 & 136.9644 & 128.4247 \\
SCSC & 117.6296 & 129.2476 & 135.318 & 141.1146 & 143.7385 \\
CSSS & 102.7485 & 106.9623 & 109.5824 & 110.3696 & 103.1902 \\
SSSC & 105.2055 & 111.0251 & 113.482 & 110.7912 & 101.8345 \\
SSCS & 103.0713 & 107.6771 & 111.8604 & 118.8297 & 123.5415 \\
SSSS & 89.8159 & 91.6626 & 94.3912 & 89.284 & 83.3021 \\
Point & 26.4022 & 26.8267 & 27.3666 & 28.542 & 30.1836 \\
supported & & & & \\
\hline$a / b=1, a / h=100, a^{\prime} / b^{\prime}=1, a / h_{h}=5, h_{l} / h_{h}=0.25, E_{11} / E_{22}=25, G_{23}=$ \\
$0.2 E_{22}, G_{13}=G_{12}=0.5 E_{22}$, and $\nu_{12}=v_{21}=0.25$. \\
\end{tabular}

For cross ply shells

Group 1: Contains CCCC, CCSC, and SCSC boundaries which exhibit relatively high frequencies.

Group 2: Contains CSCC, CCCS, CSSC, CCSS, CSCS, SSSC, CSSS, and SSCS which exhibit intermediate values of frequencies.
Group 3: Contains SSSS and corner point supported boundaries which exhibit relatively low values of frequencies.

Similarly for angle ply shells:

Group 1: Contains CCCC, CCSC, CSCC, CCCS, CSSC, CCSS, SCSC, and CSCS boundaries which exhibit relatively high frequencies.

Group 2: Contains SSSC, CSSS, SSCS, and SSSS boundaries which exhibit intermediate values of frequencies.

Group 3: Contains corner point supported shells which exhibit relatively low values of frequencies.

It is evident from the present study that the free vibration characteristics mostly depend on the arrangement of boundary constraints rather than their actual number. It can be seen from the present study that if the higher parabolic edge along $x=a$ is released from clamped to simply supported, there is hardly any change of frequency for cross ply shell. But for angle ply shells, if the edge along higher parabolic edge is released, fundamental frequency even increases more than that of a clamped shell. For cross ply shells, if the edge along $y=0$ or $y=b$ is released, that is, along the straight edges, frequency values undergo marked decrease. The results indicate that the edge along $y=0$ or $y=b$ should preferably be clamped in order to achieve higher frequency values, and if the edge has to be released for functional reason, the edge along $x=0$ and $x=a$ of a conoid must be clamped to make up for the loss of frequency. But for angle ply shells, if any two edges are released, the change in fundamental frequency is not so significant.

Tables 5 and 6 show the efficiency of a particular clamping option in improving the fundamental frequency of a shell with minimum number of boundary constraints relative to that of a clamped shell. Marks are assigned to each boundary combination in a scale assigning a value of 0 to the frequency of a corner point supported shell and 100 to that of a fully clamped shell. These marks are furnished for cutouts with $a^{\prime} / a=0.2$ These tables will enable a practicing engineer to realize at a glance the efficiency of a particular boundary condition in improving the frequency of a shell, taking that of clamped shell as the upper limit.

5.1.3. Mode Shapes. The mode shapes corresponding to the fundamental modes of vibration are plotted in Figures 4 and 5 for cross-ply and angle ply shells, respectively. The normalized displacements are drawn with the shell midsurface as the reference for all the support conditions and for all the laminations used here. The fundamental mode is clearly a bending mode for all the boundary conditions for cross-ply and angle-ply shells, except for corner point supported shell. For corner point supported shells, the fundamental mode shapes are complicated. With the introduction of cutout, mode shapes remain almost similar. When the size of the cutout is increased from 0.2 to 0.4 , the fundamental modes of vibration do not change to an appreciable amount. 
TABLE 5: Clamping options for 0/90/0/90 conoidal shells with central cutouts having $a^{\prime} / a$ ratio 0.2 .

\begin{tabular}{|c|c|c|c|}
\hline $\begin{array}{l}\text { Number of sides } \\
\text { to be clamped }\end{array}$ & Clamped edges & $\begin{array}{l}\text { Improvement of } \\
\text { frequencies with respect } \\
\text { to point supported shells }\end{array}$ & $\begin{array}{l}\text { Marks indicating the } \\
\text { efficiencies of number } \\
\text { of restraints }\end{array}$ \\
\hline 0 & Corner point supported & - & 0 \\
\hline 0 & Simply supported no edges clamped (SSSS) & Good improvement & 35 \\
\hline \multirow{3}{*}{1} & (a) Higher parabolic edge along $x=a$ (SSCS) & Marked improvement & 46 \\
\hline & (b) Lower parabolic edge along $x=0$ (CSSS) & Marked improvement & 49 \\
\hline & (c) One straight edge along $y=b$ (SSSC) & Marked improvement & 52 \\
\hline \multirow{3}{*}{2} & $\begin{array}{l}\text { (a) Two alternate edges including the higher and } \\
\text { lower parabolic edges } x=0 \text { and } x=a \text { (CSCS) }\end{array}$ & Marked improvement & 57 \\
\hline & (b) 2 straight edges along $y=0$ and $y=b$ (SCSC) & $\begin{array}{l}\text { Remarkable } \\
\text { improvement }\end{array}$ & 88 \\
\hline & $\begin{array}{l}\text { (c) Any two edges except for the above option } \\
\text { (CSSC, CCSS) }\end{array}$ & Marked improvement & 63 \\
\hline \multirow[t]{2}{*}{3} & $\begin{array}{l}3 \text { edges including the two parabolic edges (CSCC, } \\
\text { CCCS) }\end{array}$ & Marked improvement & 45 \\
\hline & $\begin{array}{l}3 \text { edges excluding the higher parabolic edge along } \\
x=a \text { (CCSC) }\end{array}$ & $\begin{array}{l}\text { Remarkable } \\
\text { improvement }\end{array}$ & 96 \\
\hline 4 & All sides $(\mathrm{CCCC})$ & $\begin{array}{l}\text { Frequency attains the } \\
\text { highest value }\end{array}$ & 100 \\
\hline
\end{tabular}

TABLE 6: Clamping options for $+45 /-45 /+45 /-45$ conoidal shells with central cutouts having $a^{\prime} / a$ ratio 0.2 .

\begin{tabular}{|c|c|c|c|}
\hline $\begin{array}{l}\text { Number of sides } \\
\text { to be clamped }\end{array}$ & Clamped edges & $\begin{array}{l}\text { Improvement of frequencies with } \\
\text { respect to point supported shells }\end{array}$ & $\begin{array}{l}\text { Marks indicating the } \\
\text { efficiencies of number of } \\
\text { restraints }\end{array}$ \\
\hline 0 & Corner point supported & - & 0 \\
\hline 0 & Simply supported no edges clamped (SSSS) & Marked improvement & 52 \\
\hline \multirow{3}{*}{1} & (a) Higher parabolic edge along $x=a$ (SSCS) & Marked improvement & 65 \\
\hline & (b) Lower parabolic edge along $x=0$ (CSSS) & Marked improvement & 64 \\
\hline & (c) One straight edge along $y=b$ (SSSC) & Marked improvement & 66 \\
\hline \multirow{3}{*}{2} & $\begin{array}{l}\text { (a) Two alternate edges including the higher and } \\
\text { lower parabolic edges } x=0 \text { and } x=a \text { (CSCS) }\end{array}$ & Remarkable improvement & 81 \\
\hline & (b) 2 straight edges along $y=0$ and $y=b$ (SCSC) & Remarkable improvement & 83 \\
\hline & $\begin{array}{l}\text { (c) Any two edges except for the above option } \\
\text { (CSSC, CCSS) }\end{array}$ & Remarkable improvement & $77-79$ \\
\hline \multirow[t]{2}{*}{3} & $\begin{array}{l}3 \text { edges including the two parabolic edges (CSCC, } \\
\text { CCCS) }\end{array}$ & Remarkable improvement & $86-89$ \\
\hline & $\begin{array}{l}3 \text { edges excluding the higher parabolic edge along } \\
x=a \text { (CCSC) }\end{array}$ & $\begin{array}{l}\text { Frequency attains more than a } \\
\text { fully clamped shell. }\end{array}$ & 107 \\
\hline 4 & All sides (CCCC) & Remarkable improvement & 100 \\
\hline
\end{tabular}

\subsection{Effect of Eccentricity of Cutout Position}

5.2.1. Fundamental Frequency. The effect of eccentricity of cutout positions on fundamental frequencies is studied from the results obtained for different locations of a cutout with $a^{\prime} / a=0.2$. The non-dimensional coordinates of the cutout centre $(\bar{x}=x / a, \bar{y}=y / a)$ were varied from 0.2 to 0.8 along each direction, so that the distance of a cutout margin from the shell boundary was not less than one tenth of the plan dimension of the shell. The margins of cutouts were stiffened with four stiffeners. The study was carried out for all the thirteen boundary conditions for both cross ply and angle ply shells. The fundamental frequency of a shell with an eccentric cutout is expressed as a percentage of fundamental frequency of a shell with a concentric cutout. This percentage is denoted by $r$. In Tables 7 and 8 , such results are furnished.

It can be seen that eccentricity of the cutout along the length of the shell towards the parabolic edges makes it more flexible. It is also seen that towards the lower parabolic edge, $r$ value is greater than that of the higher parabolic edge. This means that if a designer has to provide an eccentric cutout along the length, he should preferably place it towards the lower height boundary. The exception is there in some cases of cross ply shells. For cross ply shells with three edges simply 
TABLE 7: Values of " $r$ " for 0/90/0/90 conoidal shells.

\begin{tabular}{|c|c|c|c|c|c|c|c|c|}
\hline \multirow{2}{*}{ Edge condition } & \multirow{2}{*}{$\bar{y}$} & \multicolumn{7}{|c|}{$\bar{x}$} \\
\hline & & 0.2 & 0.3 & 0.4 & 0.5 & 0.6 & 0.7 & 0.8 \\
\hline \multirow{7}{*}{ СССС } & 0.2 & 82.951 & 90.621 & 99.503 & 101.707 & 93.088 & 85.111 & 79.437 \\
\hline & 0.3 & 82.557 & 90.021 & 99.158 & 103.034 & 93.743 & 85.175 & 79.190 \\
\hline & 0.4 & 81.946 & 89.117 & 97.773 & 101.280 & 92.554 & 84.271 & 78.405 \\
\hline & 0.5 & 81.955 & 88.983 & 97.220 & 100.015 & 91.853 & 83.955 & 78.247 \\
\hline & 0.6 & 81.946 & 89.115 & 97.771 & 101.280 & 92.555 & 84.271 & 78.405 \\
\hline & 0.7 & 82.557 & 90.020 & 99.159 & 103.036 & 93.743 & 85.175 & 79.189 \\
\hline & 0.8 & 82.887 & 90.511 & 99.407 & 101.694 & 93.070 & 85.088 & 79.424 \\
\hline \multirow{7}{*}{ CSCC } & 0.2 & 93.862 & 100.890 & 106.419 & 103.740 & 95.957 & 89.329 & 85.169 \\
\hline & 0.3 & 96.374 & 104.672 & 110.505 & 108.656 & 101.815 & 94.918 & 89.726 \\
\hline & 0.4 & 93.858 & 102.085 & 108.275 & 106.920 & 100.353 & 93.653 & 88.508 \\
\hline & 0.5 & 90.589 & 97.867 & 102.329 & 100 & 93.876 & 88.419 & 84.453 \\
\hline & 0.6 & 88.150 & 94.257 & 97.223 & 94.591 & 89.294 & 84.754 & 81.462 \\
\hline & 0.7 & 87.105 & 92.080 & 94.299 & 92.0577 & 87.583 & 83.555 & 80.475 \\
\hline & 0.8 & 87.065 & 91.375 & 93.317 & 91.458 & 87.383 & 83.527 & 80.519 \\
\hline \multirow{7}{*}{ CCSC } & 0.2 & 80.918 & 87.869 & 96.510 & 101.953 & 95.020 & 87.039 & 81.087 \\
\hline & 0.3 & 80.426 & 87.123 & 95.768 & 102.726 & 95.727 & 87.269 & 81.107 \\
\hline & 0.4 & 79.615 & 85.977 & 94.270 & 101.072 & 94.674 & 86.601 & 80.675 \\
\hline & 0.5 & 79.448 & 85.705 & 93.791 & 100 & 93.987 & 86.365 & 80.627 \\
\hline & 0.6 & 79.612 & 85.977 & 94.271 & 101.073 & 94.674 & 86.601 & 80.675 \\
\hline & 0.7 & 80.426 & 87.122 & 95.770 & 102.726 & 95.727 & 87.268 & 81.106 \\
\hline & 0.8 & 80.837 & 87.743 & 96.390 & 101.907 & 95.007 & 87.017 & 81.075 \\
\hline \multirow{7}{*}{ CCCS } & 0.2 & 87.175 & 91.751 & 93.546 & 91.679 & 87.294 & 83.462 & 80.475 \\
\hline & 0.3 & 87.180 & 92.361 & 94.480 & 92.063 & 87.489 & 83.463 & 80.416 \\
\hline & 0.4 & 88.309 & 94.562 & 97.427 & 94.587 & 89.193 & 84.660 & 81.409 \\
\hline & 0.5 & 90.816 & 98.202 & 102.571 & 100 & 93.771 & 88.341 & 84.427 \\
\hline & 0.6 & 94.105 & 102.438 & 108.564 & 106.999 & 100.349 & 93.673 & 88.565 \\
\hline & 0.7 & 96.611 & 105.025 & 110.815 & 108.872 & 101.974 & 95.062 & 89.875 \\
\hline & 0.8 & 93.762 & 101.038 & 106.545 & 103.958 & 96.168 & 89.383 & 85.123 \\
\hline \multirow{7}{*}{ CSSC } & 0.2 & 91.560 & 99.045 & 106.094 & 105.722 & 98.527 & 91.427 & 86.004 \\
\hline & 0.3 & 91.466 & 99.489 & 107.457 & 108.698 & 103.151 & 96.316 & 90.410 \\
\hline & 0.4 & 89.314 & 96.955 & 104.290 & 105.667 & 101.025 & 94.902 & 89.407 \\
\hline & 0.5 & 88.004 & 95.094 & 100.516 & 100 & 95.159 & 90.036 & 85.737 \\
\hline & 0.6 & 87.238 & 93.625 & 97.473 & 95.882 & 91.217 & 86.821 & 83.288 \\
\hline & 0.7 & 87.033 & 92.615 & 95.568 & 94.032 & 89.939 & 85.975 & 82.704 \\
\hline & 0.8 & 87.165 & 92.303 & 94.864 & 93.620 & 89.886 & 86.065 & 82.823 \\
\hline \multirow{7}{*}{ CCSS } & 0.2 & 87.339 & 92.674 & 95.098 & 93.607 & 89.769 & 85.968 & 82.749 \\
\hline & 0.3 & 87.146 & 92.875 & 95.730 & 94.015 & 89.811 & 85.845 & 82.608 \\
\hline & 0.4 & 87.407 & 93.903 & 97.657 & 95.859 & 91.084 & 86.689 & 83.196 \\
\hline & 0.5 & 88.217 & 95.390 & 100.738 & 100 & 95.034 & 89.925 & 85.675 \\
\hline & 0.6 & 89.541 & 97.258 & 104.563 & 105.762 & 101.012 & 94.895 & 89.435 \\
\hline & 0.7 & 91.697 & 99.797 & 107.751 & 108.900 & 103.289 & 96.435 & 90.531 \\
\hline & 0.8 & 91.033 & 98.862 & 106.134 & 105.856 & 98.729 & 91.447 & 85.903 \\
\hline \multirow{7}{*}{ CSCS } & 0.2 & 87.176 & 90.165 & 91.941 & 90.278 & 87.528 & 86.028 & 85.511 \\
\hline & 0.3 & 90.236 & 93.667 & 95.133 & 93.168 & 90.295 & 88.544 & 87.299 \\
\hline & 0.4 & 93.274 & 97.392 & 98.931 & 97.165 & 94.295 & 92.109 & 89.886 \\
\hline & 0.5 & 95.713 & 99.837 & 101.259 & 100 & 97.767 & 96.416 & 93.011 \\
\hline & 0.6 & 93.271 & 97.392 & 98.930 & 97.154 & 94.291 & 92.103 & 89.883 \\
\hline & 0.7 & 90.232 & 93.666 & 95.133 & 96.907 & 90.294 & 88.544 & 87.296 \\
\hline & 0.8 & 87.045 & 90.057 & 91.800 & 90.237 & 87.504 & 86.015 & 85.510 \\
\hline
\end{tabular}


TABLe 7: Continued.

\begin{tabular}{|c|c|c|c|c|c|c|c|c|}
\hline \multirow{2}{*}{ Edge condition } & \multirow{2}{*}{$\bar{y}$} & \multicolumn{7}{|c|}{$\bar{x}$} \\
\hline & & 0.2 & 0.3 & 0.4 & 0.5 & 0.6 & 0.7 & 0.8 \\
\hline \multirow{7}{*}{ SCSC } & 0.2 & 86.114 & 93.707 & 101.983 & 100.984 & 91.907 & 84.864 & 79.915 \\
\hline & 0.3 & 85.570 & 92.996 & 101.670 & 102.014 & 92.324 & 84.978 & 79.910 \\
\hline & 0.4 & 84.341 & 91.527 & 100.008 & 100.904 & 91.661 & 84.571 & 79.679 \\
\hline & 0.5 & 83.782 & 90.945 & 99.224 & 100 & 91.321 & 84.472 & 79.663 \\
\hline & 0.6 & 84.342 & 91.527 & 100.007 & 100.904 & 91.662 & 84.571 & 79.680 \\
\hline & 0.7 & 85.570 & 92.996 & 101.673 & 102.014 & 92.325 & 84.979 & 79.911 \\
\hline & 0.8 & 86.038 & 93.588 & 101.881 & 100.967 & 91.891 & 84.845 & 79.907 \\
\hline \multirow{7}{*}{ CSSS } & 0.2 & 90.957 & 94.019 & 96.237 & 95.319 & 93.007 & 91.535 & 90.574 \\
\hline & 0.3 & 93.329 & 96.650 & 98.463 & 97.318 & 95.163 & 93.907 & 92.929 \\
\hline & 0.4 & 94.987 & 98.154 & 99.743 & 99.094 & 97.663 & 96.789 & 95.576 \\
\hline & 0.5 & 96.157 & 98.431 & 100.035 & 100 & 99.376 & 99.252 & 98.900 \\
\hline & 0.6 & 94.984 & 98.155 & 99.743 & 99.092 & 97.661 & 96.784 & 95.572 \\
\hline & 0.7 & 93.325 & 96.649 & 98.463 & 97.317 & 95.162 & 93.907 & 92.926 \\
\hline & 0.8 & 90.826 & 93.898 & 96.032 & 95.227 & 92.974 & 91.510 & 90.575 \\
\hline \multirow{7}{*}{ SSSC } & 0.2 & 97.801 & 107.461 & 112.236 & 106.669 & 97.842 & 91.027 & 86.339 \\
\hline & 0.3 & 100.320 & 109.209 & 113.744 & 109.522 & 101.475 & 94.421 & 89.126 \\
\hline & 0.4 & 99.538 & 107.571 & 110.641 & 105.969 & 98.634 & 92.339 & 87.472 \\
\hline & 0.5 & 97.804 & 105.127 & 105.975 & 100 & 93.276 & 88.232 & 84.425 \\
\hline & 0.6 & 96.806 & 103.135 & 102.653 & 96.372 & 90.208 & 85.948 & 82.902 \\
\hline & 0.7 & 96.657 & 101.965 & 101.055 & 95.197 & 89.518 & 85.604 & 82.855 \\
\hline & 0.8 & 96.784 & 101.605 & 100.554 & 94.955 & 89.461 & 85.654 & 82.981 \\
\hline \multirow{7}{*}{ SSCS } & 0.2 & 93.160 & 96.470 & 95.571 & 91.662 & 88.790 & 87.812 & 87.727 \\
\hline & 0.3 & 96.515 & 99.494 & 98.334 & 94.512 & 91.801 & 90.728 & 90.027 \\
\hline & 0.4 & 99.292 & 102.150 & 101.314 & 97.900 & 95.242 & 93.801 & 92.363 \\
\hline & 0.5 & 100.559 & 103.324 & 102.905 & 100 & 97.629 & 96.284 & 94.946 \\
\hline & 0.6 & 99.290 & 102.155 & 101.314 & 97.896 & 95.240 & 93.802 & 92.362 \\
\hline & 0.7 & 96.514 & 99.481 & 98.332 & 94.512 & 91.80 & 90.726 & 90.024 \\
\hline & 0.8 & 93.059 & 96.355 & 95.442 & 91.626 & 88.753 & 87.798 & 87.733 \\
\hline \multirow{7}{*}{ SSSS } & 0.2 & 91.510 & 96.363 & 98.295 & 97.493 & 95.587 & 93.691 & 91.976 \\
\hline & 0.3 & 95.252 & 98.790 & 99.925 & 98.895 & 97.114 & 95.560 & 94.407 \\
\hline & 0.4 & 97.747 & 100.113 & 100.764 & 99.692 & 98.064 & 96.681 & 95.608 \\
\hline & 0.5 & 98.751 & 100.497 & 101.006 & 100 & 98.510 & 97.233 & 96.154 \\
\hline & 0.6 & 97.742 & 100.114 & 100.764 & 99.690 & 98.063 & 96.682 & 95.608 \\
\hline & 0.7 & 95.251 & 98.786 & 99.922 & 98.897 & 97.113 & 95.560 & 94.405 \\
\hline & 0.8 & 91.451 & 96.286 & 98.154 & 97.412 & 95.567 & 93.666 & 91.951 \\
\hline \multirow{7}{*}{ CS } & 0.2 & 137.892 & 128.050 & 114.295 & 104.647 & 100.791 & 101.361 & 109.077 \\
\hline & 0.3 & 135.205 & 125.573 & 111.227 & 101.093 & 97.006 & 97.834 & 106.312 \\
\hline & 0.4 & 132.315 & 124.337 & 110.519 & 100.187 & 95.990 & 97.045 & 105.585 \\
\hline & 0.5 & 131.075 & 123.720 & 110.365 & 100 & 95.813 & 96.912 & 105.499 \\
\hline & 0.6 & 132.292 & 124.356 & 110.550 & 100.211 & 96.017 & 97.088 & 105.603 \\
\hline & 0.7 & 135.228 & 125.582 & 111.219 & 101.090 & 96.984 & 97.817 & 106.303 \\
\hline & 0.8 & 135.480 & 125.754 & 112.435 & 102.528 & 98.801 & 99.577 & 107.915 \\
\hline
\end{tabular}

$a / b=1, a / h=100, a^{\prime} / b^{\prime}=1, a / h_{h}=5, h_{l} / h_{h}=0.25, E_{11} / E_{22}=25, G_{23}=0.2 E_{22}, G_{13}=G_{12}=0.5 E_{22}$, and $v_{12}=v_{21}=0.25$.

supported when cutout shifts towards the lower parabolic edge (including the lower parabolic edge) the shell becomes stiffer. Again for corner point supported shells, $r$ values increase towards the parabolic edges and are maximum along lower parabolic edge. For cross ply shells, four out of thirteen boundary conditions yield the maximum value of $r$ along $\bar{x}=0.5$, four yield maximum values of $r$ along $\bar{x}=0.4$, and others show maximum values within $\bar{x}=0.4$ to 0.5 .
It is observed from Table 7 that if the eccentricity of a cutout is varied along the width, the shell becomes stiffer when the cutout shifts towards clamped edges. So, for functional purposes, if a shift of central cutout is required, eccentricity of a cutout along the width should preferably be towards the clamped straight edge. For shells having two straight edges of identical boundary condition, the maximum fundamental frequency occurs along $\bar{y}=0.5$. For corner 
TABLE 8: Values of " $r$ " for $+45 /-45 /+45 /-45$ conoidal shells.

\begin{tabular}{|c|c|c|c|c|c|c|c|c|}
\hline \multirow{2}{*}{ Edge condition } & \multirow{2}{*}{$\bar{y}$} & \multicolumn{7}{|c|}{$\bar{x}$} \\
\hline & & 0.2 & 0.3 & 0.4 & 0.5 & 0.6 & 0.7 & 0.8 \\
\hline \multirow{7}{*}{ СССС } & 0.2 & 72.823 & 78.236 & 82.758 & 83.828 & 81.568 & 76.803 & 71.923 \\
\hline & 0.3 & 74.884 & 80.770 & 86.548 & 88.893 & 86.815 & 81.249 & 75.551 \\
\hline & 0.4 & 76.701 & 83.522 & 91.226 & 95.703 & 93.788 & 87.111 & 80.040 \\
\hline & 0.5 & 77.112 & 84.768 & 94.005 & 100 & 97.403 & 89.411 & 81.517 \\
\hline & 0.6 & 76.805 & 83.652 & 91.325 & 95.680 & 93.763 & 87.160 & 80.108 \\
\hline & 0.7 & 75.008 & 80.906 & 86.626 & 88.855 & 86.795 & 81.298 & 75.617 \\
\hline & 0.8 & 72.647 & 77.908 & 82.266 & 83.759 & 81.579 & 76.633 & 71.755 \\
\hline \multirow{7}{*}{ CSCC } & 0.2 & 81.077 & 91.056 & 97.803 & 91.446 & 86.032 & 83.235 & 78.655 \\
\hline & 0.3 & 83.525 & 93.130 & 102.170 & 99.590 & 94.922 & 89.192 & 82.211 \\
\hline & 0.4 & 84.074 & 93.824 & 101.696 & 103.807 & 101.498 & 94.596 & 86.412 \\
\hline & 0.5 & 83.003 & 90.427 & 97.733 & 100 & 99.474 & 96.299 & 87.547 \\
\hline & 0.6 & 81.276 & 87.968 & 94.605 & 96.334 & 95.817 & 92.081 & 84.895 \\
\hline & 0.7 & 79.646 & 86.287 & 92.866 & 94.104 & 92.136 & 86.701 & 80.220 \\
\hline & 0.8 & 78.630 & 85.619 & 92.366 & 92.585 & 89.172 & 83.321 & 77.139 \\
\hline \multirow{7}{*}{ CCSC } & 0.2 & 70.077 & 77.727 & 85.937 & 83.800 & 79.229 & 74.361 & 69.326 \\
\hline & 0.3 & 71.072 & 78.703 & 87.768 & 88.368 & 83.336 & 77.766 & 72.302 \\
\hline & 0.4 & 71.984 & 80.017 & 89.895 & 95.290 & 89.759 & 82.905 & 76.264 \\
\hline & 0.5 & 72.468 & 81.214 & 91.396 & 100 & 93.470 & 85.277 & 77.810 \\
\hline & 0.6 & 71.937 & 79.893 & 89.673 & 95.311 & 89.871 & 83.044 & 76.355 \\
\hline & 0.7 & 71.086 & 78.669 & 87.710 & 88.508 & 83.481 & 77.891 & 72.371 \\
\hline & 0.8 & 70.006 & 77.569 & 85.788 & 83.973 & 79.340 & 74.231 & 69.123 \\
\hline \multirow{7}{*}{ CCCS } & 0.2 & 78.059 & 85.085 & 91.568 & 92.620 & 90.166 & 84.849 & 78.646 \\
\hline & 0.3 & 78.792 & 85.576 & 91.983 & 93.758 & 92.489 & 87.571 & 81.169 \\
\hline & 0.4 & 80.502 & 87.433 & 93.909 & 95.951 & 95.851 & 92.337 & 85.557 \\
\hline & 0.5 & 82.841 & 90.481 & 97.657 & 100 & 99.876 & 96.861 & 88.986 \\
\hline & 0.6 & 85.401 & 94.488 & 102.330 & 104.306 & 102.177 & 96.765 & 88.819 \\
\hline & 0.7 & 85.313 & 94.803 & 103.136 & 100.952 & 96.520 & 91.365 & 84.617 \\
\hline & 0.8 & 81.938 & 91.745 & 98.552 & 93.014 & 87.371 & 84.653 & 80.319 \\
\hline \multirow{7}{*}{ CSSC } & 0.2 & 80.251 & 90.347 & 102.001 & 98.147 & 92.559 & 90.103 & 85.813 \\
\hline & 0.3 & 81.688 & 90.911 & 103.714 & 105.159 & 101.546 & 97.766 & 88.928 \\
\hline & 0.4 & 81.340 & 89.735 & 99.850 & 103.865 & 102.503 & 98.783 & 91.054 \\
\hline & 0.5 & 81.528 & 89.780 & 96.778 & 100 & 99.635 & 97.691 & 92.230 \\
\hline & 0.6 & 81.914 & 89.289 & 95.251 & 97.877 & 98.401 & 97.867 & 92.317 \\
\hline & 0.7 & 81.213 & 88.071 & 94.478 & 97.330 & 98.425 & 94.980 & 87.252 \\
\hline & 0.8 & 80.276 & 87.186 & 94.253 & 97.479 & 97.826 & 90.750 & 83.637 \\
\hline \multirow{7}{*}{ CCSS } & 0.2 & 79.271 & 85.734 & 92.215 & 96.177 & 97.750 & 92.440 & 85.311 \\
\hline & 0.3 & 80.024 & 86.471 & 92.663 & 96.147 & 97.781 & 95.350 & 88.242 \\
\hline & 0.4 & 81.065 & 87.896 & 94.083 & 97.107 & 98.178 & 97.531 & 92.578 \\
\hline & 0.5 & 82.087 & 90.360 & 97.023 & 100 & 100.117 & 98.606 & 94.251 \\
\hline & 0.6 & 82.521 & 90.825 & 101.803 & 104.549 & 103.368 & 100.351 & 93.755 \\
\hline & 0.7 & 82.941 & 91.821 & 103.719 & 105.727 & 102.486 & 99.509 & 91.399 \\
\hline & 0.8 & 80.346 & 90.089 & 100.955 & 99.195 & 93.707 & 91.345 & 87.507 \\
\hline \multirow{7}{*}{ CSCS } & 0.2 & 78.163 & 86.022 & 92.995 & 92.450 & 88.854 & 85.808 & 80.401 \\
\hline & 0.3 & 79.871 & 86.979 & 93.768 & 95.528 & 94.670 & 90.304 & 83.255 \\
\hline & 0.4 & 81.380 & 88.475 & 95.483 & 97.758 & 98.510 & 95.335 & 87.720 \\
\hline & 0.5 & 83.417 & 91.209 & 98.288 & 100 & 101.457 & 99.522 & 90.636 \\
\hline & 0.6 & 83.285 & 90.593 & 97.462 & 99.337 & 99.875 & 96.908 & 89.038 \\
\hline & 0.7 & 81.807 & 89.179 & 96.019 & 97.206 & 95.825 & 91.360 & 84.354 \\
\hline & 0.8 & 79.311 & 87.551 & 94.710 & 93.330 & 88.907 & 85.864 & 80.620 \\
\hline
\end{tabular}


TABLE 8: Continued.

\begin{tabular}{|c|c|c|c|c|c|c|c|c|}
\hline \multirow{2}{*}{ Edge condition } & \multirow{2}{*}{$\bar{y}$} & \multicolumn{7}{|c|}{$\bar{x}$} \\
\hline & & 0.2 & 0.3 & 0.4 & 0.5 & 0.6 & 0.7 & 0.8 \\
\hline \multirow{7}{*}{ SCSC } & 0.2 & 85.127 & 94.329 & 95.136 & 88.093 & 85.184 & 82.426 & 78.466 \\
\hline & 0.3 & 86.016 & 95.544 & 99.993 & 92.933 & 89.052 & 85.588 & 80.885 \\
\hline & 0.4 & 86.853 & 97.202 & 105.501 & 97.941 & 92.882 & 88.930 & 83.293 \\
\hline & 0.5 & 87.280 & 98.396 & 107.888 & 100 & 94.353 & 90.351 & 84.256 \\
\hline & 0.6 & 86.654 & 96.782 & 104.675 & 97.456 & 92.684 & 88.887 & 83.209 \\
\hline & 0.7 & 85.821 & 95.213 & 99.433 & 92.519 & 89.003 & 85.631 & 80.778 \\
\hline & 0.8 & 84.798 & 93.899 & 94.867 & 87.932 & 85.323 & 82.385 & 78.165 \\
\hline \multirow{7}{*}{ CSSS } & 0.2 & 84.944 & 92.468 & 99.487 & 102.083 & 102.496 & 102.211 & 95.697 \\
\hline & 0.3 & 87.001 & 94.415 & 100.612 & 101.921 & 103.359 & 105.519 & 99.083 \\
\hline & 0.4 & 87.482 & 95.487 & 101.492 & 100.522 & 100.612 & 102.250 & 100.822 \\
\hline & 0.5 & 87.931 & 97.254 & 102.629 & 100 & 99.420 & 100.620 & 99.680 \\
\hline & 0.6 & 88.552 & 96.975 & 102.732 & 101.723 & 101.674 & 102.885 & 100.813 \\
\hline & 0.7 & 88.608 & 96.436 & 102.875 & 103.969 & 105.120 & 106.825 & 99.475 \\
\hline & 0.8 & 85.793 & 93.995 & 101.843 & 104.209 & 103.551 & 102.657 & 95.378 \\
\hline \multirow{7}{*}{ SSSC } & 0.2 & 90.301 & 101.510 & 103.781 & 96.224 & 91.653 & 89.271 & 87.137 \\
\hline & 0.3 & 91.100 & 102.460 & 108.098 & 102.693 & 98.673 & 95.766 & 90.177 \\
\hline & 0.4 & 90.295 & 101.404 & 106.028 & 102.757 & 98.698 & 95.253 & 90.038 \\
\hline & 0.5 & 89.523 & 99.110 & 102.720 & 100 & 96.670 & 94.017 & 90.034 \\
\hline & 0.6 & 88.793 & 96.857 & 100.664 & 98.472 & 96.351 & 94.739 & 91.563 \\
\hline & 0.7 & 88.172 & 95.669 & 99.702 & 97.818 & 96.797 & 96.041 & 90.722 \\
\hline & 0.8 & 87.395 & 94.930 & 98.931 & 96.571 & 95.997 & 95.427 & 88.365 \\
\hline \multirow{7}{*}{ SSCS } & 0.2 & 88.795 & 97.759 & 99.936 & 94.981 & 92.168 & 90.694 & 87.596 \\
\hline & 0.3 & 90.150 & 98.974 & 101.928 & 98.665 & 97.216 & 96.201 & 89.404 \\
\hline & 0.4 & 91.309 & 100.310 & 103.409 & 99.753 & 97.841 & 97.300 & 92.291 \\
\hline & 0.5 & 92.288 & 101.662 & 104.357 & 100 & 97.487 & 96.678 & 93.643 \\
\hline & 0.6 & 92.516 & 101.539 & 104.514 & 100.363 & 98.033 & 97.305 & 92.917 \\
\hline & 0.7 & 91.859 & 100.918 & 103.929 & 99.899 & 98.067 & 97.444 & 90.291 \\
\hline & 0.8 & 89.927 & 99.404 & 101.683 & 95.907 & 92.707 & 91.701 & 87.789 \\
\hline \multirow{7}{*}{ SSSS } & 0.2 & 88.805 & 93.985 & 97.537 & 99.443 & 99.34104 & 97.458 & 93.660 \\
\hline & 0.3 & 90.116 & 95.853 & 98.238 & 99.300 & 99.55631 & 98.869 & 96.461 \\
\hline & 0.4 & 89.799 & 95.332 & 98.006 & 97.770 & 96.847 & 96.012 & 94.848 \\
\hline & 0.5 & 89.665 & 94.925 & 97.577 & 100 & 95.462 & 94.360 & 93.375 \\
\hline & 0.6 & 90.247 & 95.512 & 98.509 & 98.722 & 97.792 & 96.672 & 95.013 \\
\hline & 0.7 & 90.943 & 96.728 & 99.725 & 101.290 & 101.508 & 100.518 & 97.141 \\
\hline & 0.8 & 88.912 & 94.653 & 99.280 & 101.663 & 101.056 & 99.261 & 95.529 \\
\hline \multirow{7}{*}{ CS } & 0.2 & 124.611 & 120.401 & 110.994 & 104.153 & 102.644 & 103.581 & 108.893 \\
\hline & 0.3 & 120.487 & 117.591 & 108.489 & 101.849 & 100.596 & 101.659 & 107.324 \\
\hline & 0.4 & 117.053 & 116.177 & 107.584 & 100.426 & 99.256 & 100.691 & 105.789 \\
\hline & 0.5 & 115.794 & 115.786 & 107.429 & 100 & 98.788 & 100.425 & 105.330 \\
\hline & 0.6 & 118.003 & 116.844 & 107.793 & 100.623 & 99.239 & 100.341 & 105.584 \\
\hline & 0.7 & 122.490 & 118.779 & 109.260 & 102.384 & 100.470 & 100.978 & 106.534 \\
\hline & 0.8 & 122.076 & 118.091 & 109.558 & 102.712 & 101.196 & 101.869 & 107.386 \\
\hline
\end{tabular}

$a / b=1, a / h=100, a^{\prime} / b^{\prime}=1, a / h_{h}=5, h_{l} / h_{h}=0.25, E_{11} / E_{22}=25, G_{23}=0.2 E_{22}, G_{13}=G_{12}=0.5 E_{22}$, and $v_{12}=v_{21}=0.25$.

point supported shells, the maximum fundamental frequency always occurs along the boundary of the shell. All these are true for cross ply shells only. For an angle ply shell, such unified trend is not observed, and the boundary conditions and the fundamental frequency behave in a complex manner as evident from Table 8. But for corner point supported angle-ply shells also, the maximum values of $r$ are along the boundary.

Tables 9 and 10 provide the maximum values of $r$ together with the position of the cutout. These tables also show the rectangular zones within which $r$ is always greater than or equal to 95 and 90 . It is to be noted that at some other points, 
TABLE 9: Maximum values of $r$ with corresponding coordinates of cutout centre and zones where $r \geq 90$ and $r \geq 95$ for $0 / 90 / 0 / 90$ conoidal shells.

\begin{tabular}{|c|c|c|c|c|}
\hline $\begin{array}{l}\text { Boundary } \\
\text { condition }\end{array}$ & $\begin{array}{l}\text { Maximum values } \\
\text { of } r\end{array}$ & Co-ordinate of cutout centre & $\begin{array}{l}\text { Area in which the value of } \\
\qquad r \geq 90\end{array}$ & $\begin{array}{l}\text { Area in which the value of } \\
\qquad r \geq 95\end{array}$ \\
\hline CCCC & 103.036 & $\bar{x}=0.5, \bar{y}=0.7$ & $\begin{array}{c}\bar{x}=0.6 \\
0.2 \leq \bar{y} \leq 0.8\end{array}$ & $\begin{array}{c}0.4 \leq \bar{x} 0.5 \\
0.2 \leq \bar{y} \leq 0.8\end{array}$ \\
\hline CSCC & 110.505 & $\bar{x}=0.4, \bar{y}=0.3$ & $\begin{array}{c}0.3 \leq \bar{x} 0.5 \\
0.6 \leq \bar{y} \leq 0.8\end{array}$ & $\begin{array}{c}0.3 \leq \bar{x} 0.6 \\
0.2 \leq \bar{y} \leq 0.5\end{array}$ \\
\hline CCSC & 102.726 & $\begin{array}{l}\bar{x}=0.5, \bar{y}=0.3 \\
\bar{x}=0.5, \bar{y}=0.7\end{array}$ & $\begin{array}{c}\bar{x}=0.4,0.6 \\
0.2 \leq \bar{y} \leq 0.8\end{array}$ & $\begin{array}{c}\bar{x}=0.5 \\
0.2 \leq \bar{y} \leq 0.8\end{array}$ \\
\hline CCCS & 110.815 & $\bar{x}=0.4, \bar{y}=0.7$ & $\begin{array}{c}0.3 \leq \bar{x} 0.5 \\
0.2 \leq \bar{y} \leq 0.4\end{array}$ & $\begin{array}{c}0.3 \leq \bar{x} 0.6 \\
0.5 \leq \bar{y} \leq 0.8\end{array}$ \\
\hline CSSC & 108.698 & $\bar{x}=0.5, \bar{y}=0.3$ & $\begin{array}{c}0.3 \leq \bar{x} 0.5 \\
0.6 \leq \bar{y} \leq 0.8\end{array}$ & $\begin{array}{c}0.3 \leq \bar{x} 0.6 \\
0.2 \leq \bar{y} \leq 0.5\end{array}$ \\
\hline CCSS & 108.900 & $\bar{x}=0.5, \bar{y}=0.7$ & $\begin{array}{c}0.3 \leq \bar{x} 0.5 \\
0.2 \leq \bar{y} \leq 0.4\end{array}$ & $\begin{array}{c}0.3 \leq \bar{x} 0.6 \\
0.5 \leq \bar{y} \leq 0.8\end{array}$ \\
\hline CSCS & 101.259 & $\bar{x}=0.4, \bar{y}=0.5$ & $\begin{array}{c}0.3 \leq \bar{x} 0.5 \\
0.2 \leq \bar{y} \leq 0.3 \\
0.7 \leq \bar{y} \leq 0.8\end{array}$ & $\begin{array}{c}0.3 \leq \bar{x} 0.5 \\
0.4 \leq \bar{y} \leq 0.6\end{array}$ \\
\hline SCSC & 102.014 & $\bar{x}=0.5, \bar{y}=0.7$ & $\begin{array}{c}\bar{x}=0.3,0.5 \\
0.2 \leq \bar{y} \leq 0.8\end{array}$ & $\begin{array}{c}0.4 \leq \bar{x} 0.5 \\
0.2 \leq \bar{y} \leq 0.8\end{array}$ \\
\hline CSSS & 100.035 & $\bar{x}=0.4, \bar{y}=0.5$ & $\begin{array}{c}0.2 \leq \bar{x} 0.8 \\
0.2 \leq \bar{y} \leq 0.8\end{array}$ & $\begin{array}{c}0.3 \leq \bar{x} 0.6 \\
0.3 \leq \bar{y} \leq 0.7\end{array}$ \\
\hline SSSC & 113.744 & $\bar{x}=0.4, \bar{y}=0.3$ & $\begin{array}{c}0.6 \leq \bar{x} 0.7 \\
0.2 \leq \bar{y} \leq 0.4\end{array}$ & $\begin{array}{c}0.2 \leq \bar{x} 0.5 \\
0.2 \leq \bar{y} \leq 0.8\end{array}$ \\
\hline SSCS & 103.324 & $\bar{x}=0.3, \bar{y}=0.5$ & $\begin{array}{c}0.5 \leq \bar{x} 0.8 \\
0.3 \leq \bar{y} \leq 0.7\end{array}$ & $\begin{array}{c}0.2 \leq \bar{x} 0.4 \\
0.3 \leq \bar{y} \leq 0.7\end{array}$ \\
\hline SSSS & 101.006 & $\bar{x}=0.4, \bar{y}=0.5$ & $\begin{array}{c}\bar{x}=0.8 \\
0.2 \leq \bar{y} \leq 0.8\end{array}$ & $\begin{array}{c}0.2 \leq \bar{x} 0.7 \\
0.3 \leq \bar{y} \leq 0.7\end{array}$ \\
\hline CS & 137.892 & $\bar{x}=0.2, \bar{y}=0.2$ & nil & $\begin{array}{c}0.2 \leq \bar{x} 0.8 \\
0.2 \leq \bar{y} \leq 0.8\end{array}$ \\
\hline
\end{tabular}

$a / b=1, a / h=100, a^{\prime} / b^{\prime}=1, a / h_{h}=5, h_{l} / h_{h}=0.25, E_{11} / E_{22}=25, G_{23}=0.2 E_{22}, G_{13}=G_{12}=0.5 E_{22}$, and $v_{12}=v_{21}=0.25$.

$r$ values may have similar values, but only the zone rectangular in plan has been identified. This study identifies the specific zones within which the cutout centre may be moved so that the loss of frequency is less than $5 \%$ or $10 \%$, respectively, with respect to a shell with a central cutout. This will help a practicing engineer to make a decision regarding the eccentricity of the cutout centre that can be allowed.

5.2.2. Mode Shapes. The mode shapes corresponding to the fundamental modes of vibration are plotted in Figures 6, 7, 8, and 9 for cross-ply and angle-ply shells of CCCC and CCSC shells for different eccentric positions of the cutout. As CCCC and CCSC shells are most efficient with respect to number of restraints, the mode shapes of these shells are shown as typical results. All the mode shapes are bending modes. It is found that for different position of cutout, mode shapes are somewhat similar, only the crest and trough positions change.

The present study considers the dynamic characteristics of stiffened composite conoidal shells with square cutout in terms of the natural frequency and mode shapes. The size of the cutouts and their positions with respect to the shell centre are varied for different edge constraints of cross-ply and angle-ply laminated composite conoids. The effects of these parametric variations on the fundamental frequencies and mode shapes are considered in details. However, the effect of the shape and orientation of the cutout on the dynamic characters of the conoid has not been considered in the present study. Future studies will evaluate these aspects.

\section{Conclusions}

The following conclusions are drawn from the present study.

(1) As this approach produces results in close agreement with those of the benchmark problems, the finite element code used here is suitable for analyzing free vibration problems of stiffened conoidal roof panels with cutouts. The present study reveals that cutouts with stiffened margins may always safely be provided on shell surfaces for functional requirements.

(2) The arrangement of boundary constraints along the four edges is far more important than their actual number; so far the free vibration is concerned. The relative-free vibration performances of shells for different combinations of edge conditions along the four sides are expected to be very useful in decision making for practicing engineers. 
TABLE 10: Maximum values of $r$ with corresponding coordinates of cutout centre and zones where $r \geq 90$ and $r \geq 95$ for $+45 /-45 /+45 /-45$ conoidal shells.

\begin{tabular}{|c|c|c|c|c|}
\hline $\begin{array}{l}\text { Boundary } \\
\text { condition }\end{array}$ & $\begin{array}{l}\text { Maximum values } \\
\text { of } r\end{array}$ & Co-ordinate of cutout centre & $\begin{array}{l}\text { Area in which the value of } \\
\qquad r \geq 90\end{array}$ & $\begin{array}{l}\text { Area in which the value of } \\
\qquad r \geq 95\end{array}$ \\
\hline CCCC & 100.000 & $\bar{x}=0.5, \bar{y}=0.5$ & $\begin{array}{c}\bar{x}=0.4,0.6 \\
0.4 \leq \bar{y} \leq 0.6\end{array}$ & $\begin{array}{c}\bar{x}=0.5 \\
0.4 \leq \bar{y} \leq 0.6\end{array}$ \\
\hline CSCC & 103.807 & $\bar{x}=0.5, \bar{y}=0.4$ & $\begin{aligned} \bar{x} & =0.3,0.2 \leq \bar{y} \leq 0.5 \\
0.6 & \leq \bar{x} 0.7,0.3 \leq \bar{y} \leq 0.6\end{aligned}$ & $\begin{array}{l}0.4 \leq \bar{x} \leq 0.5 \\
0.3 \leq \bar{y} \leq 0.5\end{array}$ \\
\hline CCSC & 100.000 & $\bar{x}=0.5, \bar{y}=0.5$ & $\begin{array}{c}0.4 \leq \bar{x} \leq 0.6 \\
\bar{y}=0.5\end{array}$ & $\begin{array}{c}\bar{x}=0.5 \\
0.4 \leq \bar{y} \leq 0.6\end{array}$ \\
\hline CCCS & 104.306 & $\bar{x}=0.5, \bar{y}=0.6$ & $\begin{array}{r}0.4 \leq \bar{x} \leq 0.6 \\
0.2 \leq \bar{y} \leq 0.4\end{array}$ & $\begin{array}{l}0.4 \leq \bar{x} \leq 0.7 \\
0.5 \leq \bar{y} \leq 0.6\end{array}$ \\
\hline CSSC & 105.159 & $\bar{x}=0.5, \bar{y}=0.3$ & $\begin{array}{c}0.4 \leq \bar{x} \leq 0.7 \\
0.7 \leq \bar{y} \leq 0.8 \\
\bar{x}=0.8,0.4 \leq \bar{y} \leq 0.6\end{array}$ & $\begin{array}{l}0.4 \leq \bar{x} \leq 0.7 \\
0.3 \leq \bar{y} \leq 0.6\end{array}$ \\
\hline CCSS & 105.727 & $\bar{x}=0.5, \bar{y}=0.7$ & $\begin{aligned} \bar{x} & =0.5,0.7 \\
0.2 & \leq \bar{y} \leq 0.4 \\
\bar{x} & =0.3,0.8 \\
0.5 & \leq \bar{y} \leq 0.7\end{aligned}$ & $\begin{array}{c}0.5 \leq \bar{x} \leq 0.6 \\
0.2 \leq \bar{y} \leq 0.4 \\
0.4 \leq \bar{x} \leq 0.7 \\
0.5 \leq \bar{y} \leq 0.7\end{array}$ \\
\hline CSCS & 101.457 & $\bar{x}=0.6, \bar{y}=0.5$ & $\begin{array}{c}0.4 \leq \bar{x} \leq 0.7 \\
\bar{y}=0.3\end{array}$ & $\begin{array}{l}0.4 \leq \bar{x} \leq 0.7 \\
0.4 \leq \bar{y} \leq 0.7\end{array}$ \\
\hline SCSC & 107.888 & $\bar{x}=0.4, \bar{y}=0.5$ & $\begin{array}{c}0.5 \leq \bar{x} \leq 0.6 \\
0.4 \leq \bar{y} \leq 0.6\end{array}$ & $\begin{array}{l}0.3 \leq \bar{x} \leq 0.4 \\
0.3 \leq \bar{y} \leq 0.7\end{array}$ \\
\hline CSSS & 106.825 & $\bar{x}=0.7, \bar{y}=0.7$ & $\begin{array}{c}\bar{x}=0.3 \\
0.2 \leq \bar{y} \leq 0.8\end{array}$ & $\begin{array}{l}0.4 \leq \bar{x} \leq 0.8 \\
0.2 \leq \bar{y} \leq 0.8\end{array}$ \\
\hline SSSC & 108.098 & $\bar{x}=0.4, \bar{y}=0.3$ & $\begin{array}{l}0.7 \leq \bar{x} \leq 0.8 \\
0.3 \leq \bar{y} \leq 0.7\end{array}$ & $\begin{array}{l}0.3 \leq \bar{x} \leq 0.6 \\
0.2 \leq \bar{y} \leq 0.7\end{array}$ \\
\hline SSCS & 104.514 & $\bar{x}=0.4, \bar{y}=0.6$ & $\begin{array}{c}\bar{x}=0.2,0.8 \\
0.3 \leq \bar{y} \leq 0.7\end{array}$ & $\begin{array}{l}0.3 \leq \bar{x} \leq 0.7 \\
0.3 \leq \bar{y} \leq 0.7\end{array}$ \\
\hline SSSS & 101.663 & $\bar{x}=0.5, \bar{y}=0.8$ & $\begin{array}{c}\bar{x}=0.3,0.8 \\
0.2 \leq \bar{y} \leq 0.8\end{array}$ & $\begin{array}{l}0.4 \leq \bar{x} \leq 0.7 \\
0.2 \leq \bar{y} \leq 0.8\end{array}$ \\
\hline CS & 124.611 & $\bar{x}=0.2, \bar{y}=0.2$ & nil & $\begin{array}{c}0.2 \leq \bar{x} 0.8 \\
0.2 \leq \bar{y} \leq 0.8\end{array}$ \\
\hline
\end{tabular}

$a / b=1, a / h=100, a^{\prime} / b^{\prime}=1, a / h_{h}=5, h_{l} / h_{h}=0.25, E_{11} / E_{22}=25, G_{23}=0.2 E_{22}, G_{13}=G_{12}=0.5 E_{22}$, and $v_{12}=v_{21}=0.25$.

(3) The information regarding the behaviour of stiffened conoids with eccentric cutouts for a wide spectrum of eccentricity and boundary conditions for cross ply and angle ply shells may also be used as design aids for structural engineers.

\section{Notations}

$a, b$ : Length and width of shell in plan

$a^{\prime}, b^{\prime}$ : Length and width of cutout in plan

$b_{\text {st }}: \quad$ Width of stiffener in general

$b_{s x}, b_{s y}$ : Width of $X$ - and $Y$-stiffeners, respectively

$B_{s x}, B_{s y}$ : Strain-displacement matrix of stiffener

elements

$d_{\mathrm{st}}: \quad$ Depth of stiffener in general

$d_{s x}, d_{s y}:$ Depth of $X$ - and $Y$-stiffeners, respectively

$\left\{d_{e}\right\}: \quad$ Element displacement

$e: \quad$ Eccentricities of both $x$ - and $y$-direction stiffeners with respect to shell midsurface

$E_{11}, E_{22}$ : Elastic moduli
$G_{12}, G_{13}, G_{23}$ : Shear moduli of a lamina with respect to 1, 2 , and 3 axes of fibre

$h: \quad$ Shell thickness

$h_{h}$ : Higher height of conoid

$h_{l}$ : $\quad$ Lower height of conoid

$M_{x}, M_{y}: \quad$ Moment resultants

$M_{x y}: \quad$ Torsion resultant

$n p:$

$N_{1}-N_{8}: \quad$ Shape functions

$N_{x}, N_{y}: \quad$ Inplane force resultants

$N_{x y}$ : Inplane shear resultant

$Q_{x}, Q_{y}: \quad$ Transverse shear resultant

$R_{y}, R_{x y}$ : $\quad$ Radii of curvature and cross curvature of shell, respectively

$u, v, w: \quad$ Translational degrees of freedom

$x, y, z: \quad$ Local coordinate axes

$X, Y, Z: \quad$ Global coordinate axes

$z_{k}$ :

$\alpha, \beta$
Distance of bottom of the $k$ th ply from midsurface of a laminate

Rotational degrees of freedom 


$$
\begin{array}{ll}
\varepsilon_{x}, \varepsilon_{y}: & \text { Inplane strain component } \\
\phi: & \text { Angle of twist } \\
\gamma_{x y}, \gamma_{x z}, \gamma_{y z}: & \text { Shearing strain components } \\
\nu_{12}, \nu_{21}: & \text { Poisson's ratios } \\
\xi, \eta, \tau: & \text { Isoparametric coordinates } \\
\rho: & \text { Density of material } \\
\sigma_{x}, \sigma_{y}: & \text { Inplane stress components } \\
\tau_{x y}, \tau_{x z}, \tau_{y z}: & \text { Shearing stress components } \\
\omega: & \text { Natural frequency } \\
\bar{\omega}: & \text { Nondimensional natural } \\
& \text { frequency }=\omega a^{2}\left(\rho / E_{22} h^{2}\right)^{1 / 2} .
\end{array}
$$

\section{References}

[1] H. A. Hadid, An analytical and experimental investigation into the bending theory of elastic conoidal shells [Ph.D. thesis], University of Southampton, 1964.

[2] C. Brebbia and H. Hadid, Analysis of plates and shells using rectangular curved elements, CE/5/71 Civil engineering department, University of Southampton, 1971.

[3] C. K. Choi, "A conoidal shell analysis by modified isoparametric element," Computers and Structures, vol. 18, no. 5, pp. 921-924, 1984.

[4] B. Ghosh and J. N. Bandyopadhyay, "Bending analysis of conoidal shells using curved quadratic isoparametric element," Computers and Structures, vol. 33, no. 3, pp. 717-728, 1989.

[5] B. Ghosh and J. N. Bandyopadhyay, "Approximate bending analysis of conoidal shells using the galerkin method," Computers and Structures, vol. 36, no. 5, pp. 801-805, 1990.

[6] A. Dey, J. N. Bandyopadhyay, and P. K. Sinha, "Finite element analysis of laminated composite conoidal shell structures," Computers and Structures, vol. 43, no. 3, pp. 469-476, 1992.

[7] A. K. Das and J. N. Bandyopadhyay, "Theoretical and experimental studies on conoidal shells," Computers and Structures, vol. 49, no. 3, pp. 531-536, 1993.

[8] D. Chakravorty, J. N. Bandyopadhyay, and P. K. Sinha, "Free vibration analysis of point-supported laminated composite doubly curved shells-A finite element approach," Computers and Structures, vol. 54, no. 2, pp. 191-198, 1995.

[9] D. Chakravorty, J. N. Bandyopadhyay, and P. K. Sinha, "Finite element free vibration analysis of point supported laminated composite cylindrical shells," Journal of Sound and Vibration, vol. 181, no. 1, pp. 43-52, 1995.

[10] D. Chakravorty, J. N. Bandyopadhyay, and P. K. Sinha, "Finite element free vibration analysis of doubly curved laminated composite shells," Journal of Sound and Vibration, vol. 191, no. 4, pp. 491-504, 1996.

[11] D. Chakravorty, P. K. Sinha, and J. N. Bandyopadhyay, "Applications of FEM on free and forced vibration of laminated shells," Journal of Engineering Mechanics, vol. 124, no. 1, pp. 1-8, 1998.

[12] A. N. Nayak and J. N. Bandyopadhyay, "On the free vibration of stiffened shallow shells," Journal of Sound and Vibration, vol. 255, no. 2, pp. 357-382, 2003.

[13] A. N. Nayak and J. N. Bandyopadhyay, "Free vibration analysis and design aids of stiffened conoidal shells," Journal of Engineering Mechanics, vol. 128, no. 4, pp. 419-427, 2002.

[14] A. N. Nayak and J. N. Bandyopadhyay, "Free vibration analysis of laminated stiffened shells," Journal of Engineering Mechanics, vol. 131, no. 1, pp. 100-105, 2005.
[15] A. N. Nayak and J. N. Bandyopadhyay, "Dynamic response analysis of stiffened conoidal shells," Journal of Sound and Vibration, vol. 291, no. 3-5, pp. 1288-1297, 2006.

[16] H. S. Das and D. Chakravorty, "Design aids and selection guidelines for composite conoidal shell roofs-a finite element application," Journal of Reinforced Plastics and Composites, vol. 26, no. 17, pp. 1793-1819, 2007.

[17] H. S. Das and D. Chakravorty, "Natural frequencies and mode shapes of composite conoids with complicated boundary conditions," Journal of Reinforced Plastics and Composites, vol. 27, no. 13, pp. 1397-1415, 2008.

[18] S. S. Hota and D. Chakravorty, "Free vibration of stiffened conoidal shell roofs with cutouts," JVC/Journal of Vibration and Control, vol. 13, no. 3, pp. 221-240, 2007.

[19] M. S. Qatu, E. Asadi, and W. Wang, "Review of recent literature on static analyses of composite shells: 2000-2010," Open Journal of Composite Materials, vol. 2, pp. 61-86, 2012.

[20] M. S. Qatu, R. W. Sullivan, and W. Wang, "Recent research advances on the dynamic analysis of composite shells: 20002009," Composite Structures, vol. 93, no. 1, pp. 14-31, 2010.

[21] V. V. Vasiliev, R. M. Jones, and L. L. Man, Mechanics of Composite Structures, Taylor and Francis, New York, NY, USA, 1993.

[22] M. S. Qatu, Vibration of Laminated Shells and Plates, Elsevier, London, UK, 2004.

[23] S. Sahoo and D. Chakravorty, "Finite element bending behaviour of composite hyperbolic paraboloidal shells with various edge conditions," Journal of Strain Analysis for Engineering Design, vol. 39, no. 5, pp. 499-513, 2004. 

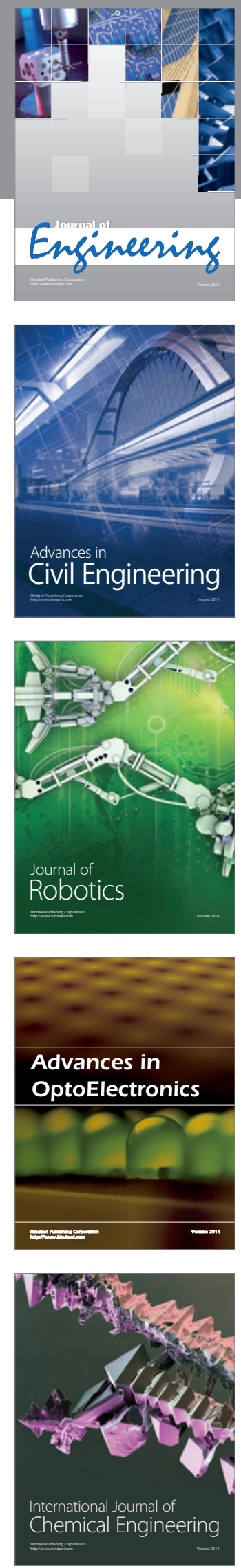

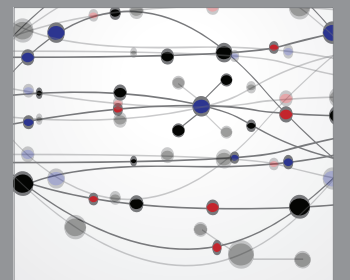

The Scientific World Journal
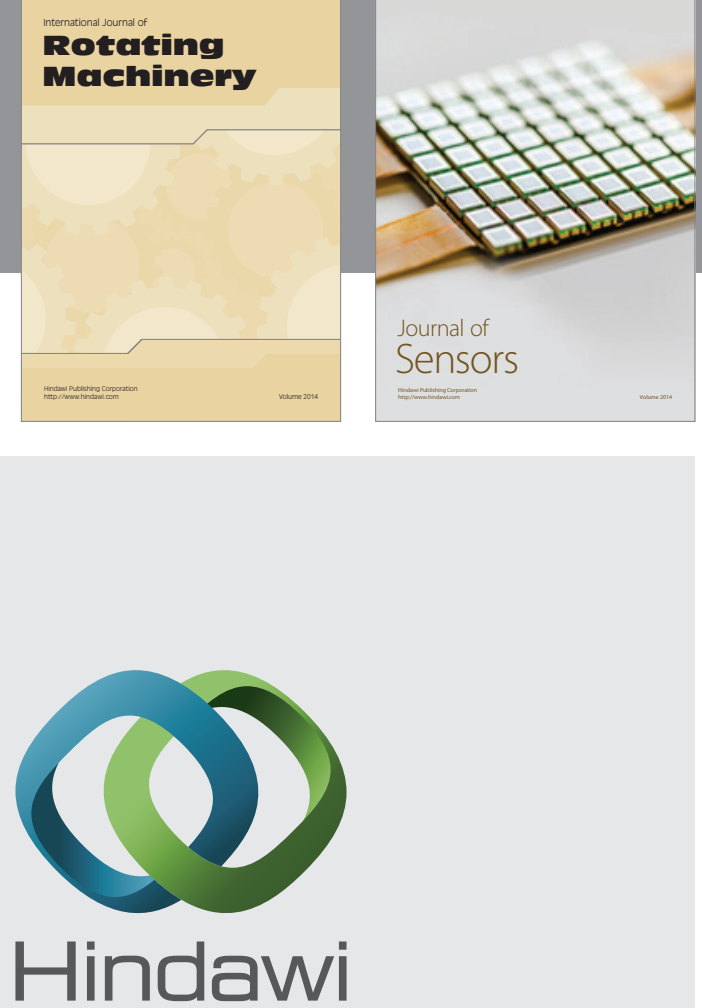

Submit your manuscripts at http://www.hindawi.com
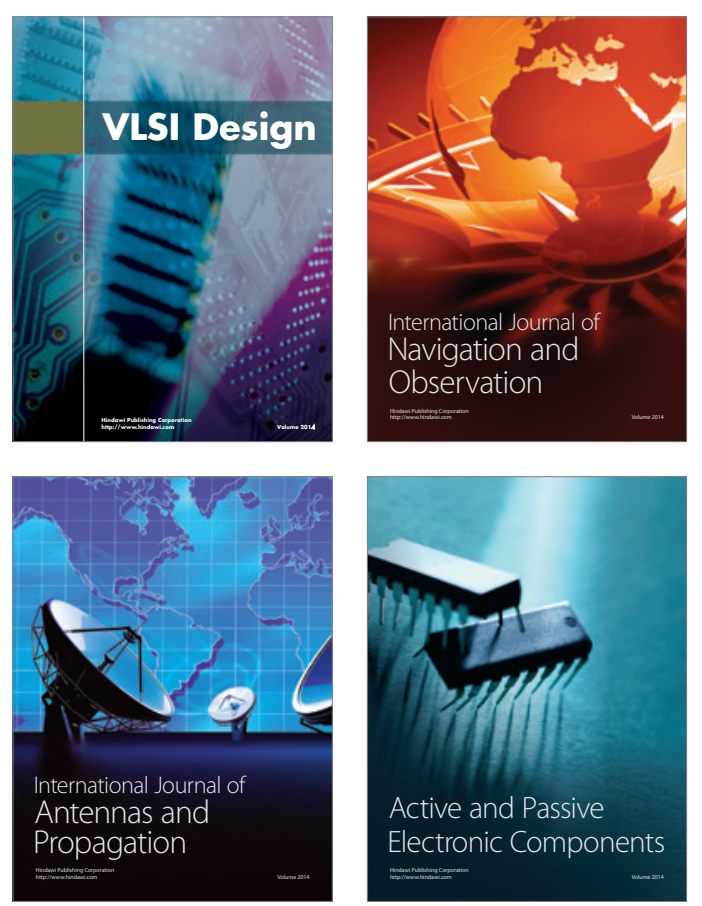
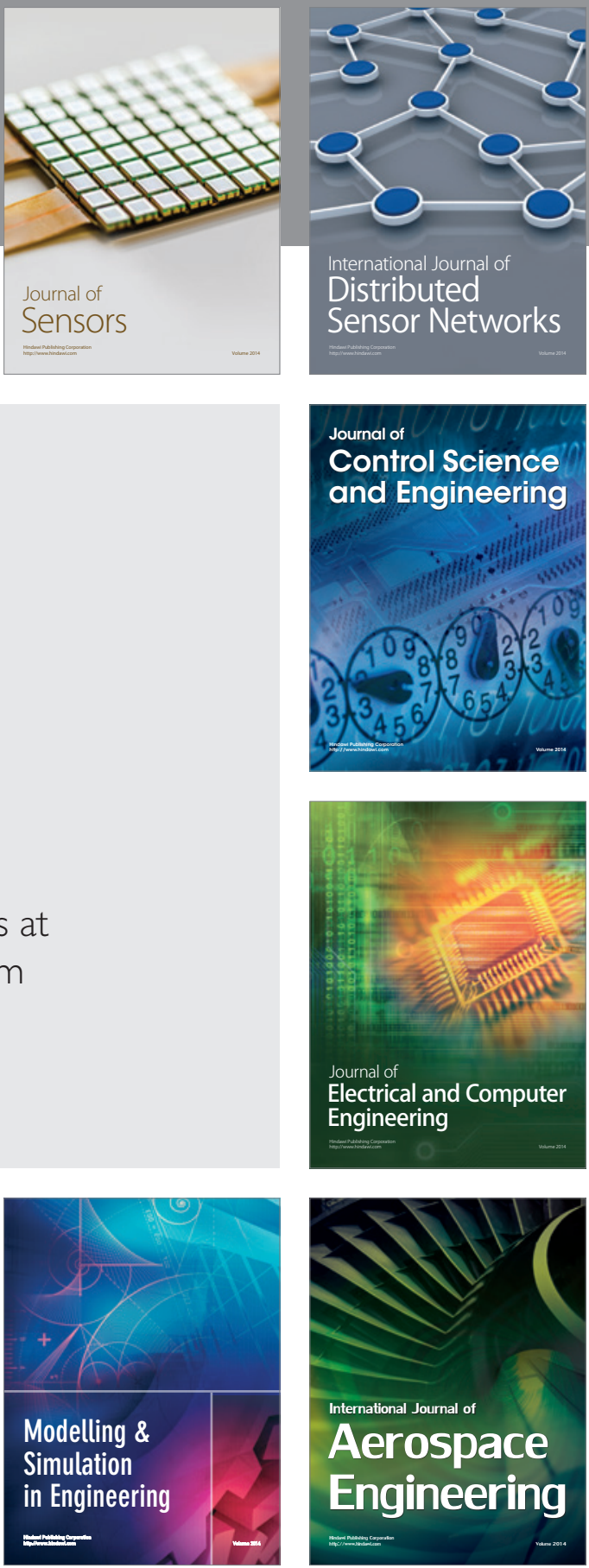

Journal of

Control Science

and Engineering
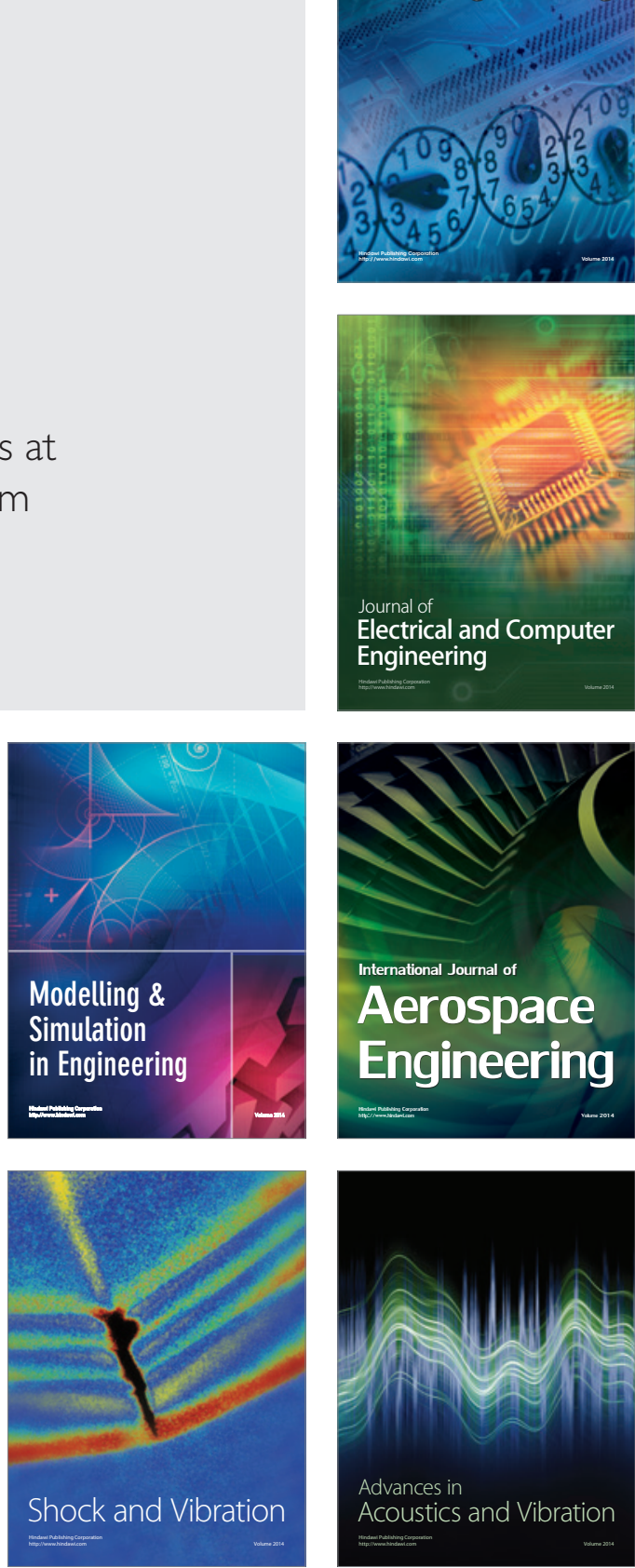